\title{
LOS DERECHOS EN EL CONSTITUCIONALISMO: TIPOLOGÍA Y TUTELA «MULTILEVEL"
}

\author{
ENRIQUE ÁLVAREZ CONDE \\ Catedrático de Derecho Constitucional \\ Universidad Rey Juan Carlos \\ ROSARIO TUR AUSINA \\ Profesora Contratada Doctora de Derecho Constitucional \\ Universidad Miguel Hernández de Elche
}

SUMARIO

I. Introducción.

II. Breves notas sobre los derechos como elementos centrales del Estado liberal. El definitivo triunfo del Estado Social.

III. Solidaridad y derechos de tercera generación.

IV. Los retos de las nuevas tecnologías: la "cuarta generación" de derechos.

$\mathrm{V}$. La tutela internacional de los derechos y el obstáculo "soberanista" para su eficacia.

VI. Una especial referencia al marco europeo de tutela de los derechos.

VII. La tutela de los derechos en los estados descentralizados. Especial referencia al papel de los Estatutos de Autonomía en el marco de la Constitución Española de 1978.

VIII. Las cartas locales de derechos: hacia una tutela "de proximidad" de los derechos.

IX. Los derechos en los ámbitos sectoriales públicos y privados.

X. Una novedad en la tutela "multilevel" de los derechos: la profundización en los deberes de la ciudadanía. 


\section{INTRODUCCIÓN}

Hoy día es posible constatar todo un proceso de internacionalización e integración progresiva del sistema de derechos fundamentales en los diferentes ordenamientos nacionales, pudiendo incluso hablarse de un derecho europeo de los derechos fundamentales ${ }^{1}$. Sin embargo, también es cierto que, simultáneamente, se ha producido un notable desarrollo de la regulación normativa de los derechos fundamentales en las normas subconstitucionales (Constituciones de Estados miembros, Estatutos de Autonomía...), en la legislación ordinaria estatal, autonómica y local, e incluso regulaciones normativas de empresas y entidades jurídico-publicas y también de carácter privado que vienen a conformar, en su conjunto, una protección multinivel de los derechos fundamentales ${ }^{2}$, pareciendo como si todos los poderes públicos y privados se hubiesen embargado en la tarea de proteger los derechos fundamentales, por lo que podría hablarse, incluso, de una competencia difusa al respecto. Es decir, la Constitución estatal parece haber perdido su monopolio y exclusividad en la defensa de los derechos fundamentales, consecuencia directa del proceso de transformación del Estado Contemporáneo a que estamos asistiendo. Todo ello plantea una importante problemática que hace adquirir una nueva dimensión a la Teoría General de los Derechos Humanos.

En efecto, las Cartas de Derechos proliferan en los variados ámbitos territoriales (internacional, estatal, regional, local) y sectoriales (servicios sanitarios, transportes, administración de justicia, códigos del buen gobierno, etc.) que, a veces, se entremezclan entre sí. Todo lo cual no deja de plantear importantes problemas jurídicos como son, entre otros, la naturaleza de los instrumentos donde se ubican estas declaraciones, el propio significado de su contenido, su eficacia, su sistema de protección, sus relaciones con otras declaraciones de derechos y con el sistema de fuentes del derecho, etc.

1 Vid. por todos, DELGADO BARRIO, J., «Proyección de las decisiones del Tribunal Europeo de Derechos Humanos en la jurisprudencia española", Revista de Administración Pública, núm. 119, 1989, que alude a "la tarea propia de los vasos comunicantes en el mantenimiento de un nivel común de reconocimiento de derechos humanos", p. 243; TUR AUSINA, R., Comunicación "La Europa de los Derechos y la articulación de las tres grandes esferas de protección: Tribunales Constitucionales - Luxemburgo- Estrasburgo" VIII Congreso de Cultura Europea, Universidad de Navarra, Pamplona 19-22 octubre 2005 (en prensa).

2 Vid. CATALÀ I BAS, A.H., "La inclusión de una carta de derechos en los estatutos de Autonomía", Revista de la Función Consultiva, núm. 4, 2006; TUR AUSINA, R., "La introducción de un catálogo de derechos en el nuevo Estatuto de Autonomía de la Comunidad Valenciana", Revista de Estudios Autonómicos, núm. 49-50, 2006; BARCELÓ, M., Derechos y deberes constitucionales en el estado autonómico, Civitas, Madrid, 1991; DE OTTO, I., "Los derechos fundamentales y la potestad normativa de las Comunidades Autónomas en la jurisprudencia constitucional", Revista Vasca de Administración Pública, núm. 10, 1984; CABELLOS ESPIÉRREZ, M.A., La distribución competencial en materia de derechos y deberes constitucionales y la incidencia del Derecho comunitario, Universitat de Barcelona, Barcelona, 2001, y "Distribución competencial y regulación de los derechos y deberes constitucionales: Posibilidades y limites del estado y Comunidades Autónomas", Revista Vasca de Administración Pública, núm. 49, 1997; TUDELA ARANDA, J., Derechos constitucionales y autonomía politica, Civitas, Madrid, 1994. 
Como bien pudo observarse en el constitucionalismo revolucionario de finales del XVIII, el reconocimiento de los derechos fundamentales y las libertades públicas es consustancial al sistema constitucional ${ }^{3}$, habiendo aparecido nuevos instrumentos de defensa de los derechos y manteniendo su condición de sistema de valores y elementos legitimadores del Estado. Los nuevos retos pudieron llegar a plantear, al respecto, la necesidad de una reforma de la Constitución en materia de derechos, cuestión que no fue prevista en el Informe del Consejo de Estado de 16 de febrero de 2006. En principio, no somos partidarios de ampliar la hipotética reforma de la Constitución a los derechos fundamentales - cuestión que podría abrir un debate interminable-, previendo un nuevo catalogo de derechos, pues aparte de que el reconocimiento internacional de los nuevos derechos puede cumplir las posibles lagunas existentes, hay que recordar que nuestra propia jurisprudencia constitucional, en la STC 290/2000, de 30 de noviembre, ha señalado que uel reconocimiento y protección de nuevos derechos fundamentales es un cometido importante de la jurisdicción constitucional, la cual, con esta ampliación de su tutela, facilita la permanencia durante largo tiempo de las Constituciones". Y ello pensando que muchos de los actuales desarrollos -internacionales, estatutarios, locales... - del sistema de derechos tienen su origen o se reconducen a los derechos fundamentales ya consagrados en la Constitución.

\section{BREVES NOTAS SOBRE LOS DERECHOS COMO ELEMENTOS CENTRALES DEL ESTADO LIBERAL. EL DEFINITIVO TRIUNFO DEL ESTADO SOCIAL.}

Con las primeras positivaciones de las libertades iniciadas a finales del siglo XviII en el continente americano y en Francia se inicia la moderna configuración de las libertades caracterizada, a grandes rasgos, por una fundamentación iusnaturalista racionalista de los derechos; el triunfo de la universalización e individualización de los derechos, desvinculándose del carácter iusprivatista de los antiguos textos; un reconocimiento de los derechos ligado íntimamente al movimiento constitucionalista del Estado Liberal al vincularse a la configuración del poder político, al que limitan; su definitiva positivización en las Constituciones ${ }^{4}$ y una clara impregnación de los dere-

3 GRIMM, D., Constitucionalismo y derechos fundamentales, Trotta, Madrid, 2006; HÄBERLE, P., Le libertà fondamentali nello Stato Costituzionale, La Nuova Storia Scientifica, Firenze, 1993 para quien "todo encasillamiento dogmático de los modelos de tutela de los derechos fundamentales y toda rigidificación dogmática son peligrosos»; FERRAJOLI, L., Derechos y garantias. La ley del más débil, Trotta, Madrid, 2002 y Los fundamentos de los derechos fundamentales, Trotta, Madrid 2003; CECCHERINI, E., La codificazione dei diritti nelle recenti Costituzioni, Giuffrè, Milano, 2002; DÍEZ-PICAZO, L.M., Sistema de Derechos Fundamentales, Civitas, Madrid, 2003; PÉREZ LUÑO, A., Derechos Humanos, Estado de Derecho y Constitución, Tecnos, Madrid, 2005.

4 Vid. por todos, FIORAVANTI, M., Los derechos fundamentales. Apuntes de historia de las Constituciones, Trotta, Madrid, 1998, pp. 55 ss. 
chos, del carácter liberal de la época, ya que son libertades "negativas" O "civiles" que pretenden conseguir la libre y privada acción del individuo, sin injerencias ni intervencionismos públicos (libre expresión, libertad y seguridad personales y en definitiva, libertad del individuo para actuar y hacer todo lo no prohibido por el Estado).

Precisamente el siglo XIX aporta una "progresiva relativización del contenido iusnaturalista de los derechos", que sirve finalmente a la burguesía para afianzar y conservar el poder político, imponiendo una lectura estatalista y "dirigista" de las libertades 5 . Y ello mientras el modelo angloamericano de derechos continúa ligado a su tradición historicista y fuertemente garantista de los mismos, donde los jueces son depositarios de la garantía de las libertades. En Estados Unidos la Constitución se impone para garantizar los derechos mientras en la Europa continental es la ley estatal, la propia autoridad gobernante quien los defiende.

En definitiva, se llega en Europa a una débil eficacia de los catálogos de derechos de las Constituciones y un retroceso de la idea de libertad como límite frente al poder, al reconducirse los derechos a la voluntad del legislador. Situación en la que también se encuentra, aunque con sus propias particularidades, el liberalismo español del XIx. Respecto a la influencia del tan citado rasgo del constitucionalismo liberal decimonónico sobre la alternancia de Constituciones progresistas y conservadoras, la llamada ley del péndulo, en materia de derechos este doble carácter no resultaría tan determinante por cuanto el marco "liberal" es el mismo, y tampoco la práctica ni el sistema de garantía de los derechos ayudarían a sostener tal diferenciación.

El individualismo y carácter abstracto del sistema de derechos evidenciará al llegar el siglo xx, las enormes deficiencias que contenía: los documentos constitucionales constituían simples proclamaciones formales que en muchos aspectos se alejaban de una realidad social presidida por la desigualdad y complicada por los cambios tecnológicos, industriales, económicos y sociales, y por los mismos desastres de la I Guerra Mundial. En definitiva, se trataba de reivindicar al Estado la garantía de existencia de condiciones básicas de vida de las personas que éstas no son capaces de lograr por sí mismas (la llamada "procura existencial" ${ }^{6}$ ): una igualdad real, que además se hiciera valer incluso frente al legislador.

Son, sin duda, las reivindicaciones obreras y socialdemócratas las que, propugnando reformas destinadas a generalizar el sufragio y la educación, condiciones más dignas en el trabajo o, en definitiva, un reparto igualitario de las cargas económicas y sociales mediante la participación en la estructura de poder del Estado, acaban ligando libertades "democráticas" (asociación, reunión, sindicación y sufragio) a las demandas sociales. Y ello aunque los de-

5 Ibidem, pp. 112 ss.; ALEXY, R., Teoría de los derechos fundamentales, Centro de Estudios Constitucionales, Madrid, 1997.

6 GARCÍA-PELAYO, M., Las transformaciones del Estado Contemporáneo, Alianza, Madrid, 1994, pp. 13 ss. 
rechos democráticos sólo aparecen esporádicamente en los Estados decimonónicos. Sólo el siglo xx transforma e incorpora estos postulados a sus Constituciones, a los que se unen, indudablemente, el otorgamiento de valor normativo superior a estos textos a través de los Tribunales Constitucionales.

Es importante destacar en este momento que esta generación de derechos sociales y económicos ha recibido un débil apoyo desde el derecho internacional, aunque quizá a nuestro juicio con la salvedad de la política social de la Unión Europea. Y ello a diferencia de los llamados derechos de tercera y cuarta generación que, sin embargo, han sido más fuertemente impulsados desde diversas organizaciones internacionales (paz, desarrollo, medio ambiente, biotecnologías, libertad informática...). Es complejo que los Estados quieran ver comprometidas sus economías a través de derechos que les exigen una fuerte inyección económica; aunque también ha de apuntarse que la globalización supone crecimiento económico, si bien, en muchos casos, selectivo?

De otra parte, también conviene señalar que, a pesar de que las más recientes Constituciones han recogido estos derechos - entre ellas la nuestra de 1978-, no lo han hecho equiparándolos en general a los clásicos derechos liberales y democráticos (con la excepción de algunos, como el derecho de huelga y el de educación) y, por ello, sin dotarlos de las garantías jurisdiccionales propias de aquéllos —que, de otro lado, son las más efectivas-; siendo, además, proclamados en la Constitución, fundamentalmente, como principios y aspiraciones socio-económicas. La cuestión no es baladí, pues entendiéndose que se está ante derechos "no absolutos" cuya eficacia y plena aplicabilidad en la práctica depende en muy buena medida de los recursos económicos con que cuenten los poderes públicos en un momento determinado, pero asimismo cuya naturaleza les lleva principalmente a marcar una serie de objetivos dejando que sean dichos poderes los que arbitren los medios para su consecución ${ }^{8}$. En definitiva, todo ello evidenciaría la tendencia a depositar en la práctica cotidiana de los gobiernos — pero también, de modo muy notable, en los poderes autonómicos y locales-, una extraordinaria responsabilidad y protagonismo en su defensa y materialización real y cotidiana?

7 Cfr. PASTOR RIDRUEJO, A., "La globalización de los derechos humanos. El reto del Siglo XXI", Revista Europea de Derechos Fundamentales, núm. 2, 2003, p. 28; GÓMEZ SÁNCHEZ, Y., Derecho Constitucional Europeo. Derechos y libertades, Sanz y Torres, Madrid, 2005, pp. 63-64.

8 Piénsese en el derecho a la vivienda, la tutela del derecho al trabajo, etc. Al respecto, ya advirtió KONRAD HESSE que era un error intentar recoger en la Constitución Alemana derechos de este tipo: "Se lee en la Constitución y a continuación, lógicamente, hay que preguntarse: ¿Qué hay de las viviendas?, con el consiguiente efecto disfuncional si dichas expectativas no se ven cumplidas. La constitución no debe prometer lo que no es capaz de cumplir". Cfr. CRUZ VILLALÓN, P., "La Ley Fundamental y la unidad de Alemania. Una conversación con Konrad Hesse", Anuario de Derecho Constitucional y Parlamentario, núm. 3, 1993.

9 En tal sentido se han manifestado tanto el Tribunal Europeo de Derechos Humanos (STEDH caso Airey, de 9 de octubre de 1979), como el Tribunal Constitucional Español (SSTC 77/1985, y 134/1987), para quienes la realización efectiva de los derechos sociales económicos depende de la situación de cada Estado, de su situación económica, y de la conjugación que los poderes públicos realicen entre los diversos valores y derechos de acuerdo con los recursos disponibles. Cfr. MARTÍNEZ ESTAY, J.I., "Los derechos sociales" art. cit., pp. 388-389. 
Las Constituciones no han sido — quizá por tratarse de postulados para cuya consecución en tanto derechos subjetivos es imprescindible la mediación inmediata y puntual de los poderes públicos-, los textos principalmente destinados a disciplinar los derechos sociales y económicos $-\mathrm{y}$ como hemos visto, parece que tampoco han encontrado en los documentos internacionales su locus idóneo-. De hecho prototipos de Constituciones como la estadounidense y la alemana no cuentan en su elenco de derechos con los de tinte social y económico ${ }^{10}$.

Prescindiendo ahora de otros posibles antecedentes historicos, la Constitución del 78 inicia una nueva fase que, en la tónica de los más modernos Estados Europeos, introduce un completo catálogo de derechos de signo liberal, democrático y económico-social ${ }^{11}$. De clara influencia alemana, italiana y portuguesa, el catálogo enfatiza — en tanto derechos subjetivos_-, la tutela de los clásicos derechos liberales y democráticos, entre los que introduce además puntuales derechos de corte económico y social (educación, sindicación y huelga); consagra en un segundo nivel — cuya garantía más relevante es la indisponibilidad frente al legislador de su contenido esencial- contenidos diversos como el matrimonio, propiedad privada, herencia, fundación, derecho al trabajo, colegios profesionales, negociación colectiva y libertad de empresa; y reduce a principios rectores de la política social y económica —destinados a informar la práctica judicial, legislativa y administrativa-, importantes compromisos socio-económicos (sobre determinados bienes: deporte, ocio, cultura, investigación, patrimonio; y colectivos: familia, trabajadores, discapacitados, juventud, tercera edad, consumidores y usuarios, organizaciones de defensa de intereses económicos), en algunos casos susceptibles de ser calificados como "expectativas de derechos" (vivienda, medio ambiente, salud,...), y en ocasiones constituyendo menciones de derechos pertenecientes, más bien, a derechos de la tercera y cuarta generación.

\section{SOLIDARIDAD Y DERECHOS DE TERCERA GENERACIÓN}

\section{Respuestas a LA CRISIS DE LAS PRIMERAs GENERACIONES DE DERECHOS}

Aunque no somos partidarios de una compartimentación exacerbada de generaciones, pues unos derechos se alimentan a otros, se completan o se corrigen, ha de señalarse que frente a los derechos de primera generación — de carácter civil y político, que tienen su génesis en la Revolución Francesa, se desarrollan durante el siglo XIX, y se conciben como derechos de defensa fren-

10 Cfr. sobre los derechos sociales, por todos, JIMENA QUESADA, L., Escritos sobre derecho europeo de los derechos sociales, Tirant lo Blanch, Valencia, 2004; GARCÍA AÑÓN, J., AÑÓN ROIG, M.J., Lecciones de derechos sociales, Tirant lo Blanch, Valencia, 2004.

11 Vid. un comentario al respecto, ÁLVAREZ CONDE, E., "El sistema constitucional español de derechos fundamentales", Corts. Anuario de Derecho Parlamentario, núm. 15, 2004, pp. 115-146. 
te a los poderes públicos-, y los derechos de segunda generación —-sociales, económicos y culturales, surgidos en el período de entreguerras en forma de mandatos dirigidos al Estado para la garantía de determinadas prestaciones que pretenden conseguir una mayor y mejor calidad de vida-, se alude a una tercera generación que pretende ofrecer una respuesta a la llamada "contaminación de las libertades", a los clásicos derechos erosionados por los nuevos retos y compromisos que aquejan al hombre en sus relaciones sociales y respecto a la naturaleza ${ }^{12}$. Si el fundamento de los derechos de primera generación era la "libertad", y el de la segunda era la "igualdad", ahora cabe hablar de la "solidaridad" (derechos de los pueblos) como base y sustrato de estos nuevos derechos, lo que implica aunar esfuerzos, responsabilidades y cooperación para responder a las necesidades y aspiraciones globales comunes que se refieren a la paz, al desarrollo y al medio ambiente, partiendo "de la totalidad de las necesidades e intereses del ser humano tal como se manifiestan en el presente, ${ }^{13}$.

Si la titularidad de los derechos de primera generación correspondía a los seres humanos individualmente considerados, y los de la segunda a los hombres en grupos, en la tercera generación se trata de atender a las globales necesidades e intereses del ser humano, que disfrutarían de estos derechos de forma solidaria y universal. También aquí - como ocurría con la segunda generación - es precisa una actitud intervencionista de los Estados garantizando determinadas prestaciones positivas o negativas, pero al propio tiempo también de la propia comunidad internacional, en tanto se trata de bienes e intereses cuya plena consecución sólo es alcanzable desde niveles que trascienden las fronteras estatales, implicando decisivamente a las organizaciones de carácter internacional. Asimismo, debe tenerse en cuenta que la naturaleza de estos derechos determina que también puedan ser titulares los propios Estados, ante otros Estados y frente a la comunidad internacional ${ }^{14}$.

\section{Clasificación}

Respecto a los derechos que se integran en esta generación, su clasificación se realiza en función del bien que protegen, de tal modo que se trata de

12 Sobre las generaciones de derechos, cfr. VASAK, K., "Les différents catégories des droits de l'homme", en LAPEYRE, A., TINGUY, F., VASAK, K., Les dimensions universelles des droits de l'homme, Vol. I, Bruylant, Bruxelles, 1990, pp. 301 ss., PÉREZ LUÑO, A.E., "Las generaciones de derechos humanos", Revista del Centro de Estudios Constitucionales, núm. 10, 1991, pp. 203-217. Sobre la tercera generación, vid. PÉREZ LUÑO, A.E., La tercera generación de derechos humanos, Aranzadi, Pamplona, 2006 - aunque este autor introduce aquí derechos ligados a las nuevas tecnologías que nosotros consideramos de "cuarta" generación-.

13 Ibidem, pp. 34-36.

14 AGUILAR CUEVAS, M., "Las tres generaciones de los derechos humanos", Derechos $\mathrm{Hu}$ manos. Órgano informativo de la Comisión de Derechos Humanos del Estado de México, núm. 30, 1998, p. 98. 
derechos sustentados en tres pilares: 1) Paz (autodeterminación, independencia política, identidad nacional y cultural, coexistencia pacífica, patrimonio común de la humanidad, entendimiento y confianza, asistencia humanitaria); 2) Desarrollo (independencia económica, cooperación internacional y regional, justicia social internacional, solución de problemas alimenticios, demográficos, educativos, etc., progreso y desarrollo industrial y tecnológico); 3) Medio ambiente (desarrollo sostenible, derecho al agua aprovechamiento racional de los recursos hídricos-, al patrimonio común de la humanidad, a la biodiversidad y bioseguridad, y al acceso a los entornos naturales).

Debido quizá a la dimensión "interestatal" que en muchos casos adquieren estos derechos, ha sido en el ámbito internacional donde han tenido un apoyo notable, pues sucesivos seminarios y conferencias internacionales han sido organizados al efecto por la ONU, la UNESCO y diversas organizaciones internacionales, donde han podido perfilarse estos derechos. El paso siguiente ha sido una paulatina - aunque no completa-, incorporación de estos derechos a los documentos internacionales. Así, a modo de ejemplo, en la Carta Africana de Derechos Humanos (1981), cuya mayor parte de sus disposiciones son derechos de tercera generación; y distintas resoluciones de los organismos de Naciones Unidas, aunque en este punto es todavía una cuenta pendiente la proclamación de un "Pacto Internacional de Derechos de Solidaridad", en idéntico sentido a como fueron aprobados Pactos y Declaraciones relativos a las dos anteriores generaciones de derechos — si se quiere con menor énfasis en la segunda generación- ${ }^{15}$.

\section{a) La paz}

Respecto al análisis en particular de los derechos que se integran en cada uno de los pilares que sustentan esta tercera generación, sobre la paz es obvio que se viene asistiendo a una temática de indudable trascendencia internacional, como así se evidencia al erigirse la paz y seguridad en el fin primordial de Naciones Unidas. En efecto, corresponde a esta organización el mantenimiento de la paz y la seguridad internacional —incluidas las cuestiones referidas al desarme-, el fomento de las relaciones amistosas entre los pueblos, y del arreglo pacífico de las controversias internacionales. De otro lado, de acuerdo con la resolución 377 —Unión Pro Paz A/RES/377-, adoptada por la Asamblea General en noviembre de 1950, la Asamblea podría tomar medidas si el Consejo de Seguridad, faltando la unanimidad de sus miembros, no adopta decisión alguna ante una amenaza, quebrantamiento de

15 Documento que fue incluso elaborado, aunque su aprobación definitiva no ha tenido lugar. KUNICKA-MICHALSKA, B., "Derecho al medio ambiente como el derecho humano de la tercera generación", Jurídica. Anuario del Departamento de Derecho de la Universidad Iberoamericana, núm. 22, 1993, pp. 470-472. 
la paz, o acto de agresión. En tal sentido, se faculta a la Asamblea a conocer del asunto con carácter inmediato a fin de recomendar a los Miembros la adopción de medidas colectivas, incluido el empleo de la fuerza si fuera necesario $^{16}$.

\section{b) El desarrollo}

Respecto al pilar relativo al "desarrollo" se pretende responder a la insuficiencia y debilidad de la proclamación y puesta en práctica de los derechos económicos, sociales y culturales, así como a la inestabilidad social y política proveniente de minoritarios grupos en el poder; circunstancias que provocan la aparición de movimientos subversivos y guerrillas contra el régimen establecido, y que perpetúan la constante vulneración de derechos ${ }^{17}$. La vorágine en que se ven inmersos estos Estados lleva, pues, a la defensa internacional de una necesaria cooperación al desarrollo de carácter integral para estos países, que ha tenido un punto de apoyo importante en labor ejercida por $\mathrm{Na}$ ciones Unidas $^{18}$. Al respecto, cabría destacar, centrando la atención en los últimos acontecimientos, los compromisos contraídos en la "Declaración del Milenio" (2000), los objetivos de desarrollo fijados, a continuación, por la Secretaría de Naciones Unidas, y el "Consenso de Monterrey" (2002) respaldando la Declaración del Milenio. Compromisos todos ellos revisados en la Reunión Plenaria de Alto Nivel de la Asamblea General de Naciones Unidas de 2005 ("Cumbre del Milenio + 5"). En general, se define el campo de actuación consensuado a nivel internacional en materia de lucha contra la pobreza y de desarrollo, si bien los objetivos van más allá y afectan también a los otros dos pilares (paz y medio ambiente). En particular, la Declaración del Milenio fijaría, a grandes rasgos, los siguientes objetivos — con fecha límite del 2015-: la erradicación de la pobreza extrema y el hambre; la universalización de la enseñanza primaria universal; la promoción de la igualdad entre los sexos y la autonomía de la mujer; la reducción de la mortalidad de los niños menores de 5 años; la mejora de la salud materna; la lucha contra el VIH/SIDA, el paludismo y otras enfermedades; la garantía de la sostenibilidad del medio ambiente; y el fomento de una asociación mundial para el desarrollo. Todo ello, a partir de la proclamación de ciertos valores fundamentales en las relaciones internacionales del siglo xxi: libertad, igualdad, solidaridad, tolerancia, respeto de la naturaleza, y responsabilidad común. La

16 VACAS FERNÁNDEZ, F., El régimen jurídico del uso de la fuerza por parte de las operaciones de mantenimiento de la paz de Naciones Unidas, Marcial Pons, Madrid, 2005; FERNÁNDEZ SÁNCHEZ, P.A., Operaciones de las Naciones Unidas para el mantenimiento de la paz, Universidad de Huelva, Huelva, 1998.

17 PASTOR RIDRUEJO, A., "La globalización...” art. cit., p. 25.

18 Cfr. VIÑAS, A., "La cooperación al desarrollo en las Naciones Unidas: planteamientos actuales", Sistema: Revista de Ciencias Sociales, núm. 127-128, 1995, pp. 79-90. 
última de las cumbres supuso un intento de reavivación política del impulso necesario para lograr un progreso más rápido y eficaz, al tiempo que seguir profundizando en el citado fomento de una asociación mundial para el desarrollo en la que Naciones Unidas fuera sede principal de debates y consensos.

\section{c) El medio ambiente}

En torno al "medio ambiente" se plantea la necesidad de una adecuada atención a las relaciones del hombre con su entorno natural: la búsqueda de un uso equilibrado de los recursos naturales y una utilización racional de los recursos energéticos al objeto de procurar y hacer posible una mayor y mejor calidad de vida para los seres humanos.

$\mathrm{Al}$ respecto, es preciso hacer referencia en el marco de Naciones Unidas a la "Cumbre para la Tierra y Agenda 21" (Río de Janeiro, 1992), donde se integran las principales cuestiones sobre el desarrollo sostenible siguiendo para ello los Principios de la "Declaración de Río sobre el Medio Ambiente y el Desarrollon: la contaminación de la atmósfera, el aire y el agua, la lucha contra la deforestación; la desertificación y la pérdida de terrenos agrícolas, la lucha contra la reducción de las poblaciones de peces, y la promoción del manejo seguro de los desechos sólidos ${ }^{19}$. Para ello, esta Agenda 21 se centra en aquellos elementos que especialmente afectan al medio ambiente como la deuda externa, las modalidades insostenibles de producción y consumo, la estructura económica mundial, la presión demográfica, y la pobreza. Asimismo, se recomienda la participación de grupos considerados relevantes para la consecución de dicho desarrollo sostenible, como agricultores, jóvenes y niños, mujeres, comunidad científica, autoridades locales, empresas e industrias, organizaciones no gubernamentales, etc. A partir de este Programa, numerosos Estados han elaborado planes nacionales (que a su vez han dado lugar a Agendas 21 locales), además de haber servido para la elaboración de diversos Tratados sobre pesca, desertificación, diversidad biológica, y cambio climático. Con posterioridad, la Cumbre Mundial sobre el Desarrollo Sostenible celebrada en Johannesburgo en el año 2002, revisó los avances y carencias de la Cumbre del año 1992, con la finalidad de hacer frente a los retos planteados en sectores como alimentación, agua, vivienda, sanidad, energía, salud y seguridad económica ${ }^{20}$.

19 En esta cumbre se acuñó el concepto de "desarrollo sostenible" para referirse a aquel que asegura las necesidades del presente sin comprometer la capacidad de las generaciones futuras de satisfacer las propias.

20 Sobre la cumbre de Johannesburgo, vid. el número 33 de la Revista Medi Ambient -Generalitat de Catalunya - (2002): http://www.gencat.net/mediamb/revista/rev33-cast.htm (25 de octubre de 2006). 
La Unión Europea, en política de medio ambiente ha mostrado una notable preocupación ${ }^{21}$. Recepcionando la doctrina de Naciones Unidas en torno al concepto de "desarrollo sostenible", se proclama como objetivo de la Unión la política medioambiental, poniendo en marcha una verdadera estrategia global para el desarrollo más sostenible —Cumbre de Gotemburgo de 2001—, y depositando en el Consejo Europeo la ejecución de esta estrategia, que ha de ser revisada anualmente sobre la base de los "Informes de síntesis", en los que cabe encontrar cuarenta indicadores en torno a factores sociales, económicos y ambientales ${ }^{22}$. De otro lado, tras la Cumbre de Johannesburgo, la Unión emitiría el año siguiente una Comunicación (23 de diciembre de 2003), destinada a realizar el seguimiento en el marco europeo, de los resultados y objetivos plasmados en aquella cumbre. En los sucesivos Consejos Europeos adoptados con posterioridad, la Unión ha seguido proclamando la voluntad de cumplir con los compromisos marcados en Johannesburgo, la Declaración del Milenio, el Protocolo de Kioto sobre el cambio climático, y la Conferencia de Monterrey.

Si se desciende a los textos constitucionales se observa de inmediato que la atención prestada ha sido, sin lugar a dudas, menor. Las mayores referencias se encuentran al último de ellos, el dedicado al medio ambiente. De hecho, centrando la atención en nuestra Carta Magna, ésta alude a él como principio rector de la política social y económica en el art. 45, al disponerse que "Todos tienen derecho a disfrutar de un medio ambiente adecuado para el desarrollo de la persona, así como el deber de conservarlo", previsión que se completa con el mandato dirigido a los poderes públicos para velar por la utilización racional de los recursos naturales, con la finalidad de proteger y mejorar la calidad de vida y defender y restaurar el medio ambiente, apoyándose en la indispensable solidaridad colectiva. El precepto se cierra con la remisión al legislador para establecer las sanciones penales y administrativas convenientes, así como la reparación del daño causado, por parte de quienes violen lo dispuesto en los apartados anteriores del artículo ${ }^{23}$. Sin lugar a dudas, el desarrollo de este derecho ha adquirido en el ordenamiento español una proyección novedosa gracias a la jurisprudencia del Tribunal Europeo de Derechos Humanos que, apoyándose en diversos preceptos relativos a la in-

21 Vid. los trabajos de RIECHENBERG, K., NAVAS CASTILLO, F., YABAR STERLING, A., y FONTANA PUG, A. en la obra colectiva, ÁlVAREZ CONDE, E., GARRIDO MAYOL, V., Comentarios a la Constitución Europea, Tirant lo Blanch - Consejo Jurídico Consultivo de la Comunitat Valenciana, 2004 (3 tomos). Asimismo, TEROL BECERRA, M., "Sobre la idea de medio ambiente perceptible en el Tratado por el que se establece una Constitución para Europa", Revista de Derecho Político, núm. 65, 2006, pp. 61-90.

22 JIMÉNEZ BELTRÁN, D., "La estrategia de desarrollo sostenible de la Unión Europea en el contexto global: de Río a Johannesburgo", Información Comercial Española, ICE: Revista de Economía, núm. 800, 2002.

23 Vid. CANOSA USERA, R., Constitución y medio ambiente, Dykinson, Madrid, 2000; LÓPEZ RAMÓN, F., "El medio ambiente en la Constitución Española", Revista de derecho urbanistico y medio ambiente, núm. 39, 2005, pp. 183-198. 
violabilidad del domicilio, la intimidad y el respeto a la vida privada, ha tutelado el entorno vital del individuo y, con ello, el derecho al disfrute de una calidad de vida medioambiental digna ${ }^{24}$.

\section{LOS RETOS DE LAS NUEVAS TECNOLOGÍAS: LA “CUARTA GENERACIÓN"DE DERECHOS}

\section{El «REDIMENSIONAMIENTO» DE LOS ClÁSICOS DERECHOS}

Al progreso social y moral del ser humano no han podido serles indiferentes los cambios y avances tecnológicos. Nuevos modos de vida, nuevas dimensiones sobre los clásicos derechos y nuevos valores emergen de la revolución tecnológica y científica, obligando a marcar límites precisos más allá de los cuales resultarían afectados los derechos de las personas y, en consecuencia, la esencia del constitucionalismo. En esta fase de la evolución de los derechos se abre ahora "el camino para un gran reto añadido en el siglo xxi: las nuevas formas que cobran los derechos de primera, segunda y tercera generación en el entorno del ciberespacio, es decir, la cuarta generación de los derechos humanos ${ }^{25}$, que no ha dejar atrás la esencia del ser humano, redefiniendo el status jurídico de la persona a la luz de los avances tecnológicos.

Los derechos de cuarta generación o derechos "frente a las nuevas tecnologías" han recibido un impulso decisivo desde los Estados pero, de modo si se quiere más acusado, por parte de diversos documentos internacionales y supranacionales, lo que puede resultar explicable, de un lado, por la dimensión globalizadora que alcanzan las nuevas tecnologías y la necesidad de que la respuesta a los retos que plantean a las libertades deba necesariamente trascender el ámbito nacional. Pero, igualmente, por la singular tensión riesgos-beneficios que conllevan dichas tecnologías para el ser humano: «al lado de dinámicas positivas, también surgen mecanismos de dominación y ataques a los derechos humanos en este ciberespacio que tienen que ver con la limitación del acceso a las condiciones técnicas, económicas o culturales que permitirían el desarrollo de formas más avanzadas de participación pública y de intercambio y libre expresión de las ideas y creencias ${ }^{26}$.

$24 \mathrm{Al}$ respecto, SSTEDH caso López Ostra vs. España (9 de diciembre de 1994), y caso Moreno Gómez vs. España (14 de noviembre de 2004), que tutelaron a los particulares frente a la perturbación causada por olores e inmisiones sonoras.

25 BUSTAMANTE DONAS, J., "Hacia la cuarta generación de Derechos Humanos: repensando la condición humana en la sociedad tecnológica", Revista Iberoamericana de Ciencia, Tecnología, Sociedad e Innovación, núm. 1, 2001; GONZÁLEZ, G., Derechos Humanos: La condición bumana en la sociedad tecnológica, Tecnos, Madrid, 1999.

26 BUSTAMANTE DONAS, J., "Hacia la cuarta generación...”, art. cit. 


\section{Clasificación}

En esta nueva generación puede realizarse la siguiente distinción, teniendo en cuenta que constituyen no tanto nuevos derechos sino, fundamentalmente, nuevas dimensiones de derechos ya existentes a los que se les plantean recientes e importantes retos ${ }^{27}$ :

1) Derechos que consagran un nuevo estatuto jurídico de la vida y la integridad fisica y psíquica: vida (pena de muerte y estatuto jurídico del preembrión, embrión y feto), integridad física y psíquica (retos biotecnológicos), autodeterminación física (tratamientos médicos, consentimiento informado), igualdad en las aplicaciones biomédicas, identidad genética (clonación, información genética), a disponer de la propia vida (suicidio, eutanasia), reproducción humana (derechos procreativos), a la protección eficaz de la salud, a la investigación y aplicación técnica y científica biomédica.

2) Derechos relacionados con la globalización de las comunicaciones: derechos de la comunicación y la información (a una información completa y veraz, acceso a información de relevancia para la humanidad, a la información genética, a comunicar por cualquier medio, acceso a medios técnicos de comunicación públicos y privados, a la autodeterminación informativa, y a la protección de datos), derechos en la red (derechos informáticos, a conocer la identidad del emisor de opiniones e información, a la vida privada, intimidad y honor en la red, a la propia imagen en la red, derechos de propiedad intelectual en la red), derechos de los menores ante las nuevas tecnologías informativas y de la comunicación (protección de la infancia, acceso a la cultura a través de los medios de comunicación e información).

\section{a) Biotecnología}

En materia "biotecnológica", es indudable que el avance de la ciencia —con apoyo en diversos tratados internacionales y en nuestro propio art. $44 \mathrm{CE}-$, al tiempo que enormes beneficios para el progreso del ser humano y para su salud, puede alterar y mutar los clásicos derechos, e incluso hacer surgir nuevas perspectivas y dimensiones ${ }^{28}$. Así cabría destacar, en primer lugar, su notable incidencia sobre el derecho a la intimidad, pues las biotecnologías plantean la amplia disponibilidad y posibilidad de uso de los datos relativos a la salud. Desde esta perspectiva, se apunta la existencia de un derecho a la información, acceso y control por parte de los ciudadanos de sus datos médicos, pero también de sus datos genéticos, lo que lleva a la necesidad de ar-

27 En este punto seguimos la clasificación de GÓMEZ SÁNCHEZ, Y., Derecho Constitucional Europeo... op. cit., pp. 66-68, que introduce en esta generación el medio ambiente, inserto a nuestro juicio, en la tercera generación.

28 CASADO, M., Bioética, derecho y sociedad, Trotta, Madrid, 1998; CASADO, M., (Comp.) Estudios de bioética y derecho, Tirant lo Blanch, Valencia, 2000. 
bitrar un habeas data sanitario (habeas genoma) ${ }^{29}$. Al respecto, habría de tener en cuenta la Declaración Internacional sobre Datos Genéticos Humanos (2003), que establece los principios destinados a disciplinar el tratamiento, utilización y conservación de los datos genéticos y proteómicos, y las muestras biológicas humanas. Pero sobre todo, centrando la atención en la dignidad del ser humano, el derecho a la vida y si integridad física y psíquica, los Estados vienen aprobando en los últimos años numerosas leyes en materia de técnicas de reproducción asistida, trasplantes, investigación biomédica, donación e investigación con embriones-preembriones, etc, que colocan en un difícil debate ético-jurídico a las fuerzas políticas y sociales.

En cualquier caso, desde la legislación más "liberal" — historicista, casuista, judicialista- (Reino Unido, Estados Unidos), a la más "estatalista" —individualista, legicentrista- (Francia, Italia, Alemania), reflejando pues las dos importantes corrientes y tradiciones constitucionales a las que aludimos en un epígrafe anterior, y pasando por la española que aunque inserta en esta última tradición realiza una apuesta fuerte por el apoyo al progreso científico, lo cierto es que constituyen un marco de innegable referencia los diversos documentos internacionales aprobados en Naciones Unidas, en el Consejo de Europa y, más recientemente, en la Unión Europea ${ }^{30}$. Así, la Declaración Universal sobre el Genoma Humano y los Derechos Humanos de 11 de noviembre de 1997, aprobada en la 29. ${ }^{a}$ Conferencia General de la UNESCO, que se erige sobre el pilar de la dignidad humana, convierte en patrimonio de la humanidad el genoma humano - que intenta marcar límites a la patentabilidad y comercialización del genoma-, y proclama toda una serie de principios destinados a procurar la indemnidad de los derechos humanos frente a las actuaciones sobre el genoma (no discriminación, autonomía individual consentimiento previo, libre e informado, confidencialidad-, principios de primacía de los derechos, libertad de investigación, prudencia y responsabilidad, solidaridad y cooperación $)^{31}$. De otro lado, merece destacarse el Convenio sobre derechos humanos y biomedicina, de 4 de abril de 1997 (Convenio de Oviedo), que implica un decisivo compromiso del Consejo de Europa por sacar a la luz la necesidad de afrontar los retos y riesgos que para las personas y sus derechos puede conllevar el desarrollo científico. Un desarrollo que exige el respeto a la dignidad humana y al ser humano como persona, aunque sin negar el progreso que aportará. Partiendo del valor primario que corresponde al ser humano, el Convenio tutela específicos derechos ligados a las biotecnologías como la vida, el acceso equitativo a los beneficios que aporta la sanidad, derecho a la vida privada y consentimiento informado, y no

29 RUIZ MIGUEL, C., "Los datos sobre características genéticas: libertad, intimidad y no discriminación", en VV.AA., Genética y derecho, CGPJ, Madrid, 2001, pp. 13-68.

30 BELLVER CAPELLA, V., "Los derechos fundamentales ante la biomedicina", Revista Europea de Derechos Fundamentales, núm. 4, 2004, pp. 69-98.

31 Cfr. HERNÁNDEZ PLASENCIA, J.U., "Bases de la declaración universal sobre el Genoma Humano y los Derechos Humanos", en VV.AA., Genética y derecho, CGPJ, Madrid, 2001, pp. 105-132. 
discriminación. Para ello, se consagran específicos deberes y obligaciones para los profesionales de la biomedicina, así como determinados límites y restricciones a las prácticas biotecnológicas. Al Convenio se suma, además, el Protocolo adicional de 12 de enero de 1998, que prohibió la clonación de seres humanos.

Por último, merece una atención el art. II-63 del ya fallido proyecto de Constitución Europea sobre el derecho a la integridad de la persona que, ubicado en el capítulo referido a la dignidad, establece toda una serie de límites que necesariamente han de respetarse en el ámbito de la medicina y la biología: el consentimiento libre e informado de la persona afectada, y la prohibición de las prácticas eugenésicas - en particular las que pretenden la selección de personas-, de que el cuerpo humano o sus partes se conviertan en objeto de lucro, y de la clonación reproductora de seres humanos ${ }^{32}$.

\section{b) Informática e Internet}

En lo que afecta al ámbito de las comunicaciones y de la información, es indudable que la informática y el uso de Internet, ha supuesto una irremediable expansión planetaria de la libertad de expresión y de la transmisión de información y datos sin fronteras: una globalizada sociedad de la información. Internet puede ser, de hecho, el instrumento más favorecedor de los derechos liberales, democráticos, sociales, y solidarios, pero también su naturaleza eminentemente abierta y expansiva lleva dentro de sí un extraordinario potencial lesivo de esos mismos derechos si no existen unas fronteras precisas ${ }^{33}$. La manipulación, uso descontrolado y abuso de los datos personales, así como una comunicación que escapa de los clásicos medios de control, corren el riesgo de poner en jaque el sistema de derechos y libertades (dignidad humana, intimidad, honor, libertad de expresión e información, etc.); lo que lleva al reconocimiento del derecho a la libertad informática y a la facultad de autodeterminación en la esfera informática, pero igualmente a la necesidad de arbitrar medios, no sólo de tutela y adecuada protección de todos los derechos implicados, sino también de procurar que la libertad informática sea efectivamente extendida a todas las personas ${ }^{34}$. Como expone PÉREZ LUÑO, Internet plantea una interesante y preocupante paradoja, pues al mismo tiempo que permite la

32 Asimismo, en el ámbito de la Unión, las directivas 95/46/CE, de 24 de octubre sobre la protección de datos personales, 98/44/CE, de 6 de julio sobre protección jurídica de las invenciones biotecnológicas, y 98/79/CE, de 7 de diciembre sobre productos sanitarios para el diagnóstico in vitro.

33 BUSTAMANTE DONAS, J., "Hacia la cuarta..." art. cit.

34 Vid. entre otros, FERNÁNDEZ ESTEBAN, M.L., Nuevas tecnologías, Internet y derechos fundamentales, McGraw-Hill, Madrid, 1998; PÉREZ LUÑO, A.E., "Internet y la garantía de los derechos fundamentales", en BELLO PAREDES, S.A., MURILLO VILLAR, A., Estudios jurídicos sobre la sociedad de la información y nuevas tecnologías con motivo del XX Aniversario de la Facultad de Derecho de la Universidad de Burgos, Universidad de Burgos, Burgos, 2005, pp. 11-40; VERA 
transmisión de información sin límites, se encuentra con la difícil y fraccionada respuesta nacional a los abusos y lesiones contra derechos y libertades ${ }^{35}$.

De otro lado, constituye también una problemática de difícil encaje las técnicas informáticas destinadas a combatir la criminalidad organizada, que en ocasiones rozan la frontera de las intromisiones de ciertos derechos y muy especialmente, de la intimidad ${ }^{36}$. Al respecto, diversas han sido las respuestas ofrecidas desde el ordenamiento jurídico. En nuestro sistema jurídico, se alude al recurso del Código Penal que sancionaría (art. 301), así como el art. 186, referido a la venta y exhibición de material pornográfico a menores e incapaces.

Trascendiendo el ámbito interno, ha de destacarse en el seno de la Unión Europea la directiva 95/46/CE, del Parlamento Europeo y del Consejo, de 24 de octubre de 1995, sobre protección de las personas físicas respecto al tratamiento y libre circulación de datos personales ${ }^{37}$, la 2002/58/CE, de 12 de julio de 2002, relativa al tratamiento de los datos personales y a la protección de la intimidad en el sector de las comunicaciones electrónicas; e igualmente, la Comunicación de la Comisión sobre contenidos ilícitos y nocivos en Internet (octubre 1996). En todos estos casos, al objeto de proteger la intimidad de las personas frente al tratamiento y circulación de datos, y destacando la necesidad de que, al margen de la aplicación de las propias políticas internas, tenga lugar una intensa cooperación judicial para frenar la criminalidad en Internet, así como la proclamación de criterios europeos mínimos acerca de los contenidos criminales en la red. Por otra parte, merece igualmente destacarse el Libro Verde sobre la protección de los menores y de la dignidad bumana en los nuevos servicios audiovisuales y de información, que abarca cualquier medio audiovisual y que, aunque cita específicamente a los menores, se dirige en general a la protección de la dignidad humana ${ }^{38}$.

Recogiendo el propósito de tutelar los derechos de los ciudadanos humanos, el proyecto de Constitución Europea - que traslada el contenido de la Carta de Niza del 2000 - acogía el derecho a la vida privada (art. II-67) y la libertad de expresión (art. II-71), y quizá por constituir una proclamación más directa, la protección de los datos de carácter personal (art. II-68) que se erige en garantía de la intimidad de las personas frente a los abusos a través de Internet.

SANTOS, J.M., "Derechos fundamentales, Internet y nuevas tecnologías de la información y de la comunicación", en GARCÍA MEXÍA, P., Principios de derecho de Internet, Tirant lo Blanch, Valencia, 2002, pp. 189-246.

35 PÉREZ LUÑO, A.E., La tercera generación... op. cit., p. 94.

36 Así, los programas Echelon y Carnivore; el primero de ellos es un sistema de interceptación mundial de las comunicaciones, y el segundo es un sistema de software y hardware que permite localizar y perseguir las comunicaciones de Internet. Ibidem., pp. 97 ss.

37 Vid. al respecto, la jurisprudencia del Tribunal de Justicia de la Unión Europea, sentencia de 6 de noviembre de 2003.

38 La citada normativa ha de completarse con el Informe Construir la sociedad europea de la información para todos (2001), y Europa 2005: una sociedad de la información para todos (2002). 
Especialmente ligado con los objetivos delineados por la Unión Europea estaría también la tutela dispensada desde el marco del Consejo de Europa, ya que constituyen un notable apoyo los arts. 8 y 10 del Convenio de Roma dedicados, específicamente, al respeto de la vida privada y familiar y a la libertad de expresión, pero sobre todo la profusa jurisprudencia dictada al efecto por el Tribunal de Estrasburgo y recogida en el seno de la Unión Europea por las diversas resoluciones citadas ${ }^{39}$.

De otro lado, no cabe negar tampoco las implicaciones que las nuevas tecnologías tienen sobre los derechos de tercera generación: tanto los peligros y riesgos de deterioro del medio ambiente ocasionado por sustancias químicas peligrosas; como incluso la paz, teniendo en cuenta los riesgos derivados de los conflictos atómicos, o de las tecnologías radioactivas.

\section{LA TUTELA INTERNACIONAL DE LOS DERECHOS Y EL OBSTÁCULO "SOBERANISTA" PARA SU EFICACIA}

La tutela de los derechos ha tenido un significativo marco de referencia en la positivización que trasciende el ámbito estatal para afectar y abarcar a una multiplicidad de países a través de su internacionalización ${ }^{40}$, en lo que ha podido llamarse la "concepción ética o moral de la globalización" ${ }^{41}$. En sus orígenes, se trata de un cambio que obedece, básicamente, a las continuas y reiteradas violaciones de los derechos en las etapas de las dos guerras mundiales de principios del siglo xx, así como a la necesaria respuesta a las terribles experiencias autoritarias y totalitarias de algunos Estados. Pero además ello propiciado por un renovado iusnaturalismo que universaliza los derechos más allá del positivismo estatal — que corre el riesgo de mostrarse arbitrario en ocasiones-, y por una gradual y consciente relativización de la soberanía estatal. El reconocimiento internacional de los derechos ejercerá, sin lugar a dudas, una notable presión sobre los ordenamientos estatales, que se ven coadyuvados a procurar un reconocimiento preciso y una más eficaz tutela interna de las libertades. De este modo, las declaraciones internacionales de derechos vendrán a conformar una especie de ius commune que homogeneiza los derechos y libertades estatales ${ }^{42}$. Aunque parece, en principio, un derecho básico o un derecho mínimo, en ocasiones contienen referencias más progresistas que las propias declaraciones nacionales, dependiendo del lugar y el momento en que

39 SSTEDH Handyside vs. Reino Unido (1976), The Sunday Times vs. Reino Unido (1979), Groppera Radio (1990), o Informationsverein Lentia (1993).

40 Cfr. VILlán DURÁN, C., Curso de Derecho Internacional de los Derechos Humanos, Trotta, Madrid, 2006; SUDRE, F., Droit internacional et européen des droits de l'homme, Presses universitaires de France, Paris, 2001.

41 PASTOR RIDRUEJO, A., "La globalización...” art. cit., p. 20.

42 PÉREZ TREMPS, P., "La protección de los derechos fundamentales por jueces y tribunales", Poder Judicial núms. 43-44, 1996, pp. 267-268. 
aquél va surgiendo, por ejemplo, si se piensa en los retos que plantean las nuevas tecnologías. Las declaraciones internacionales son un mínimo irreductible para los Estados - y fundamentalmente la Declaración Universal de Derechos Humanos de 1948 y los Pactos de derechos civiles y políticos, y de derechos con referencias genéricas a valores como la dignidad, libertad e igualdad, junto a un catálogo de derechos liberales, democráticos y breves referencias a ideales socio-económicos y los Pactos de derechos civiles y políticos, y de derechos económicos, sociales y culturales de 1966- pero también objetivo a alcanzar cuando el propio catálogo interno de derechos se muestre, en algún punto, más conservador o menos innovador que el texto internacional ${ }^{43}$.

Por contraposición a los mecanismos estatales, la tutela internacional de los derechos "adolece" de una cierta singularidad, pues mientras la garantía jurisdiccional estatal es una tónica habitual, a nivel internacional aquélla constituye más bien una excepción, siendo en el plano declarativo donde sin lugar a dudas la tutela de los derechos se encuentra generalizada y constituye un referente inexcusable. Las declaraciones de derechos se completan con instrumentos de tutela caracterizados, no por reaccionar frente a las lesiones de derechos, sino básicamente por instaurar un control preventivo y cautelar para su salvaguarda, por lo que cabe diferenciar entre mecanismos "consultivos" - recomendaciones a los Estados para que adopten una actitud determinada ante una situación de especial gravedad para los derechos-, y de carácter decisorio - en forma de resoluciones obligatorias para los Estados que las asumen como tales.

No obstante, en un ámbito como el internacional ha sido una constante la dificultad por implantar mecanismos que, efectiva y directamente, fiscalicen la actividad lesiva para los derechos que se produce en el interior de los Estados. Así se constata de la puesta en práctica del «Programa de Derechos Humanos" de Naciones Unidas que viene llevando a cabo una misión de control preventivo concretada en la promoción y creación de las condiciones efectivas para el ejercicio real de los derechos, el desarrollo y coordinación de acciones destinadas a su implantación, la asistencia técnica y financiera a los Estados y organizaciones, el asesoramiento y elaboración de estudios, y el impulso de una cooperación internacional en la materia. A partir del mayor compromiso de los Estados con la "causa internacional", se ha intentado profundizar en el incremento de la obligatoriedad de las acciones internacionales y la fiscalización de las actividades lesivas de los derechos humanos, siendo no obstante la nota dominante de mecanismos convencionales y extraconvencionales para su eficacia, la persuasión, publicidad, presión e influencia capaces de generar ${ }^{44}$; y ello al margen de la eficacia más directa — dada su na-

43 DÍEZ-PICAZO, L.M., "Notas sobre la tutela de los derechos fundamentales a nivel europeo", en ROMBOLI, R., La tutela dei diritti fondamentali davanti alle Corti Costituzionali, Giappichelli, Torino, 1994, pp. 213-214.

44 Vid. FERRER LLORET, J., Responsabilidad internacional del Estado y Derechos Humanos, Tecnos, Madrid, 1998. 
turaleza judicialista-, proveniente de los Tribunales Penales Internacionales. Estas observaciones nos llevan a señalar que la efectividad de la tutela de los derechos en el ámbito internacional sigue siendo la auténtica cuenta pendiente, aunque la respuesta no es fácil pues la soberanía estatal sigue siendo una barrera insalvable, por lo que es preciso continuar atendiendo al refuerzo de las autoridades internacionales, el perfeccionamiento de los mecanismos de tutela, las obligaciones de los Estados en la salvaguarda de los derechos humanos, y el aseguramiento de su protección ${ }^{45}$.

\section{UNA ESPECIAL REFERENCIA AL MARCO EUROPEO DE TUTELA DE LOS DERECHOS}

Quizá más incisiva y eficaz es la tutela de los derechos procedente de las diversas declaraciones supranacionales que se imponen a determinados conjuntos de Estados unidos por rasgos geográficos y culturales comunes. De hecho, en el ámbito europeo el Consejo de Europa y la Unión Europea han venido a reforzar significativamente el estándar estatal de protección de los derechos ${ }^{46}$ : en el primer caso como objetivo inicial directo, y en el segundo, derivado de la idea de procurar una unión más comprometida políticamente, al tiempo que se constataba que a la económica "Europa de los mercaderes" no le resultaban ajenos los derechos humanos ${ }^{47}$.

\section{El Consejo de Europa}

El «Convenio Europeo de protección de los derechos humanos y de las libertades fundamentales" (1950), de corte liberal y democrático, nace como respuesta frontal y directa al régimen totalitario nazi, y se completa con posterioridad por diversos Protocolos, que introducen - aunque no en un modo excesivamente generoso-, los derechos sociales y económicos.

La virtud de este sistema, sin embargo, no proviene tanto de la carta de derechos del Convenio, que no difiere en exceso de lo previsto en otras declaraciones internacionales o en los mismos catálogos estatales -incluso un tanto necesitada de actualizarse debido a los cambios acontecidos desde su

45 CARRILLO SALCEDO, J.A., "Responde la Declaración Universal de 1948 a las exigencias actuales de los derechos humanos?", en VV.AA., (FERNÁNDEZ SÁNCHEZ, P.A., Ed.), La desprotección internacional de los Derechos Humanos, Universidad de Huelva, Huelva, 1998, pp. 22-23.

46 Cfr. FREIXES SANJUAN, T., «La integración en Europa y el refuerzo de las garantías de los derechos fundamentales", Revista Europea de Derechos Fundamentales, núm. 1, 2003; vid. diversos trabajos en CORCUERA ATIENZA, J., La protección de los Derechos Fundamentales en la Unión Europea, Dykinson, Madrid, 2002.

47 DUVERGER, M., La Europa de los hombres. Una metamorfosis inacabada, Alianza, Madrid, 1994. 
proclamación, momento en el que se dio prioridad a derechos civiles y políticos $^{48}$ - sino, fundamentalmente, del cauce jurisdiccional de protección ante el Tribunal Europeo de Derechos Humanos — con poder coactivo y sancionador frente a las lesiones, y autor de una importante doctrina constitucional en materia de derechos-, que ha permitido alcanzar las mayores cotas de efectividad (arts. 19 a 51 del Convenio) ${ }^{49}$; ello auspiciado por el reducido espacio geográfico de esta organización, y por la homogeneidad de los Estados que la integran.

No obstante lo expuesto, parece indudable que el punto débil de esta tutela proviene de la limitada capacidad de acción de la sentencia estimatoria dictada por el Tribunal pues, al margen la declaración de obligatoriedad ex art. 45 del Convenio, sabido es la sentencia no posee fuerza ejecutiva en España sino, en principio, meramente declarativa del derecho lesionado. Es decir, las resoluciones del Tribunal no pueden declarar la nulidad del acto o resolución lesiva ni ejercer ningún tipo de condena por el que se dirija un determinado mandato de actuación destinado al Estado, excepto la condena al pago de una indemnización: es decir, una fórmula compensatoria y sustitutiva - propia de los tratados de arbitraje y conciliación- ${ }^{50}$, configurada como pronunciamiento subsidiario, de la reparación in natura. La inexistencia de fuerza ejecutiva de las resoluciones del Tribunal de Estrasburgo es, simplemente, la consecuencia lógica del modo en que se configuran las relaciones internacionales, extremadamente respetuosas con la soberanía de los Estados a los que, por esta misma razón, se les da la capacidad para adoptar las medidas internas y crear los procedimientos de ejecución precisos a fin de dar cumplimiento a la obligaciones estatales que se desprenden de las resoluciones del Tribunal. En definitiva, forzando la colaboración de los Estados a fin de conseguir ya no tanto obligaciones de comportamiento, como obligaciones de resultado ${ }^{51}$.

$48 \mathrm{Si}$ bien se destaca que la doctrina del Tribunal de Estrasburgo ha realizado una notable prolongación de los derechos hacia su vertiente más social y económica al tiempo que de la combinación de la noción de "obligación positiva" junto con el mandato de igualdad del Convenio, han dado lugar a una importante jurisprudencia de carácter social. Cfr. JIMENA QUESADA, J., Sistema europeo de derechos fundamentales, Cólex, Madrid, 2006, pp. 44-45.

49 Frente a los instrumentos más bien "políticos" de otras organizaciones internacionales, la "movilización de la vergüenza" — principalmente se está pensando en Naciones Unidas—, se da aquí la oportunidad de una tutela más incisiva, aunque también es cierto que este mecanismo jurisdiccional sólo se ha instaurado para los derechos civiles y políticos. Cfr. PASTOR RIDRUEJO, A., "La globalización..." art. cit., p. 23.

50 BUJOSA VADELL, L.M., Las sentencias del Tribunal Europeo de Derecho Humanos y el ordenamiento español, Tecnos, Madrid, 1997, pp. 116 ss.

51 Vid. LATTANZI, F., "Struttura dei rapporti internazionali e limiti dei procedimenti di garanzia istituiti con la Convenzione Europea dei Diritti dell'Uomo", en VV.AA., (CARLASSARE, L., ed.), Le garanzie giurisdizionale dei diritti fondamentali, Cedam, Padova, 1988, p. 69. Podría afirmarse, nos recuerda RUIZ MIGUEL, que "la sentencia internacional es jurídicamente obligatoria; pero nunca es ejecutiva"; y en particular, la sentencia del Tribunal de Estrasburgo es obligatoria, definitiva, y no ejecutiva (La ejecución de las sentencias del Tribunal Europeo de Derechos Humanos, Tecnos, Madrid, 1997, pp. 28-29). 
De otro lado, respecto a los derechos económicos y sociales, ha de destacarse la "Carta Social Europea" en 1961, que supone la puesta en marcha e impulso de la idea de progreso social al consagrar toda una serie de derechos y principios sociales, si bien en un modo un tanto abierto y difuso: derecho al trabajo, negociación colectiva, sindicación, seguridad social, asistencia social y médica, derecho de la familia a una protección social, jurídica y económica, derechos de los trabajadores emigrantes, etc.; y que ha sido significativamente actualizada en el año 1996. Pero sobre todo, debiendo tomar en consideración que los mecanismos de garantía de la Carta están más debilitados al limitarse, fundamentalmente, al control sobre la base de informes nacionales.

\section{LA Unión EuROPEA}

En el mismo ámbito, pero en el seno de la Unión Europea, la omisión de los derechos humanos en los Tratados constitutivos, unida a la problemática situación planteada por los Tribunales Constitucionales Alemán e Italiano —que negaban la superioridad del derecho comunitario cuando afectaba a los derechos de sus ciudadanos ${ }^{52}$ - acabó presionando al mismo Tribunal de Justicia de esta organización, que cambió su doctrina para admitir el respeto de las tradiciones constitucionales de los Estados miembros en materia de derechos fundamentales, así como para acabar por incorporarlos a su propio ordenamiento a través de la vía pretoriana de considerar los derechos como principios generales del derecho comunitario. Las aportaciones del Tribunal de Justicia tendrían finalmente su reflejo en el Tratado de Maastricht de 1992, que en su artículo F ( $6 \mathrm{nn}$ ), apartado 2, recogió expresamente la voluntad de la Unión de respetar los derechos de conformidad con el Convenio de Roma de 1950, y dentro de las tradiciones constitucionales de los Estados miembros. El Tratado de Amsterdam de 1997 añade en este tema la posibilidad ofrecida a las instituciones comunitarias para acudir al Tribunal de Justicia en supuestos de violación de derechos por los Estados miembros.

La última etapa está representada por la aprobación de la "Carta de los Derechos Fundamentales" - Carta de Niza, 2000—, impulsada precisamente por el vacío legal en esta materia, por la necesidad de otorgar a las libertades dispersas por la normativa comunitaria el específico rango de derechos y proceder a una uniformización, y por la indefinición y discusiones sobre la carencia de eficacia jurídica del art. F.2 del Tratado de Maastricht. El texto acoge de un modo ciertamente completo derechos básicos, libertades de corte liberal y de talante democrático, político y social, al tiempo que busca también la

52 Sentencias Solange I (29 de mayo de 1974), Solange II (22 de octubre de 1986), del Tribunal Constitucional Alemán, y Frontini (27 de diciembre de 1973) de la Corte Constitucional Italiana. Vid. en general MATIA PORTILLA, F.J., La protección de los derechos fundamentales en la Unión Europea, Civitas, Madrid, 2002. 
incorporación de nuevos derechos que trascienden las clásicas formulaciones de los textos constitucionales e internacionales: igualdad de mujeres y hombres, derechos de las minorías lingüísticas, culturales,..., derechos de cuarta generación referidos a la protección de la integridad física y psíquica del ser humano y que se relacionan con las nuevas tecnologías (clonación, prácticas eugenésicas, etc.), la protección de los datos personales, etc. ${ }^{53}$.

Se ha destacado en numerosas ocasiones que la cuestión más relevante era la determinación de su eficacia o alcance: normativo, o meramente programático. Constatado el hecho de que negarle su eficacia jurídica implica la pérdida de toda efectividad práctica al impedirse que la vulneración de los derechos pueda ser directamente alegada ante los Tribunales, con su consecuente desprotección, era indudable que la tutela más completa provendría de la creación de mecanismos jurisdiccionales específicos de protección de los derechos ante el Tribunal de la Unión Europea; una especie de amparo para cuya consagración era preciso, en todo caso, un arduo consenso por parte de los Estados miembros al que no se ha llegado, efectivamente, con el proyecto de Constitución Europea ${ }^{54}$. Y ello aunque de todos modos cabe siempre la posibilidad de que el Tribunal de Justicia de la Unión Europea siga aplicando en sus resoluciones ${ }^{55}$, los derechos establecidos en la Carta como principios generales del Derecho Comunitario ${ }^{56}$, contribuyendo así a hacer más real la idea de que el Tribunal de Luxemburgo se ha consagrado como una especie de "Tribunal Constitucional" de derecho comunitario ${ }^{57}$. El proyecto de Constitución Europea, no obstante, sí di una respuesta positiva al reconocimiento de

53 Sobre esta evolución, vid. SOUTO PAZ, J.A., «La constitucionalización de los derechos fundamentales en la Unión Europea", Revista Europea de Derechos Fundamentales, núm. 1, 2003, pp. 19-37.

54 Cfr. CARMONA CONTRERAS, A.M., "El poder judicial europeo: renovación versus continuidad", en GÓMEZ CORONA, E., GUTIÉRREZ VEGA, P., LEÑERO BOHÓRQUEZ, R. (coords.), Una Constitución para la ciudadanía de Europa, Aranzadi, Pamplona, 2004. Éste fue uno de los puntos de debate en los grupos de trabajo de la Convención teniendo en cuenta, además, que ya la Propuesta XII del Informe del Comité de Sabios creado en los años 95-96 propuso que en lugar de la adhesión al Convenio de Roma se creara un recurso especial para la protección de derechos. Finalmente se optó por una solución de compromiso consagrada en el art. I-29 del Proyecto de Tratado de Constitución Europea, que prevé que serán los Estados quienes establezcan las vías de recurso necesarias para garantizar la tutela judicial efectiva en el ámbito del Derecho de la Unión, por lo que la tutela se hace descansar en los propios Estados y no en las instituciones comunitarias.

55 ZAGREBELSKY, G., Diritti e Costituzione nell'Unione Europea, Laterza, Roma-Bari, 2003.

56 De este modo, aunque de la Carta se deduzca un extraordinario valor político, también posee una notable "vocación jurídica", como instrumento hermenéutico o fuente de inspiración para las instituciones comunitarias (derecho formalmente no vinculante, soft law). Cfr. la ponencia de GARRIDO MAYOL, V., "Reconocimiento y garantía de los derechos fundamentales en el marco de la Unión Europea", aprobada por el Consejo de la Generalitat Valenciana para el debate sobre el futuro de Europa (creado por Decreto 85/2002, de 20 de mayo, del Gobierno Valenciano), en sesión de 29 de abril de 2003 (ponencia cedida por su autor); RODRÍGUEZ, A., Integración Europea y Derechos Fundamentales, Civitas, Madrid, 2001, p. 229; SALINAS DE FRÍAS, A., La protección de los Derechos Fundamentales en la Unión Europea, Comares, Granada, 2000.

57 DÍEZ-PICAZO, L.M., “Notas sobre la tutela...” art. cit., pp. 223 ss., para quien el modelo comunitario de tutela de los derechos resulta de una combinación de los modelos de justicia 
la citada eficacia normativa de la $\operatorname{Carta}^{58}$; si bien con matices, pues el art. 51 de la Carta se limita a proclamar la obligación de respeto y promoción de los derechos por las instituciones europeas y los Estados única y exclusivamente, como no podía ser de otro modo, cuando apliquen el derecho de la Unión, sin crear el catálogo competencias ni misiones nuevas.

Una cuestión pendiente es también la posibilidad y el modo en que el Derecho Comunitario y el Convenio de Roma $-\mathrm{y}$ con ello las dos instancias jurisdiccionales supremas que los garantizan-, puedan llegar a articularse para la tutela de los derechos a nivel europeo, teniendo en cuenta los diferentes standards que han llegado a aplicar ante la tutela de un mismo derecho, e incluso el control que en ciertas ocasiones ha ejercido el Tribunal de Estrasburgo sobre el derecho comunitario mediante la aplicación que de éste realizan los Estados miembros - Caso Matthews contra Reino Unido, de 18 de febrero de 1999-59. Al margen de la solución final, lo cierto es que hasta el momento la Unión Europea no ha podido ratificar el Convenio por negar tener competencias en la materia; ni el Tribunal de Estrasburgo ha admitido denuncias contra las instituciones comunitarias, aunque sí parece quedar abierto el camino para que este Tribunal conozca de las lesiones de derechos cometidas por un Estado en el ejercicio de competencias comunitarias - caso Matthews $^{60}$ - La conexión más clara, sin embargo, entre ambos ordenamientos ha tenido lugar a través del propio Tribunal de Justicia de la Unión Europea, al incorporar el Convenio y la doctrina de Estrasburgo por la citada vía de los principios generales. En los últimos tiempos el debate sobre esta cuestión ha tendido a incrementarse. La reciente potenciación de los derechos en la Unión Europea a través de la Carta —y el propio compromiso ya existente

constitucional difusa y concentrada. Este último, en cuanto existe un control directo y abstracto de los actos del Derecho Comunitario derivado ante el Tribunal de Justicia Europeo según la legitimación ejercida por los Estados miembros y las instituciones de la Unión; pero es un control difuso porque el ciudadano tendría siempre acceso al órgano de judicial review - los órganos judiciales internos - para la aplicabilidad del ordenamiento comunitario. Todo ello, serviría en definitiva para acentuar el carácter de genuinos derechos subjetivos de los derechos fundamentales en el ordenamiento comunitario".

58 No puede decirse que la Carta esté federalizada, por lo que su contenido vincula en principio desde el estricto ejercicio de las competencias comunitarias - ya sea por la Unión o por los Estados que aplican el derecho comunitario-, aunque la Carta tiene una importancia y eficacia adicional frente a los Estados miembros que, en una indudable construcción de un derecho constitucional europeo, pueden verse compelidos a plasmar en sus documentos internos - legislación, Estatutos de Autonomía o futuras reformas constitucionales- los nuevos derechos (o nuevas dimensiones), recogidos por el catálogo europeo como compromisos indudablemente aceptados y en cierto modo consensuados.

59 Vid. TUR AUSINA, R., "La Europa de los Derechos..." art. cit.; SANZ CABALLERO, S., "Interferencias entre el Derecho Comunitario y el Convenio Europeo de Derechos Humanos (Luxemburgo vs. Estrasburgo: ¿quién es la última instancia de los derechos fundamentales?", Revista de Derecho Comunitario Europeo, núm. 17, 2004.

60 RIDEAU, J., "La coexistence des sistèmes de protection des droits fondamentaux dans la Communauté Européenne et ses États Membres", Annuaire International de Justice Constitutionnelle, VII-1991, Económica-PUAM, pp. 61-63. 
de los Estados miembros con el Convenio de Roma en tanto la Unión obliga a los Estados al respeto de los derechos para integrarse en ésta organización, constituyendo dicho Convenio una fuente privilegiada de inspiración- ${ }^{61}$, todo ello parece aconsejar una clarificación del sistema de tutela europeo de los derechos e igualmente plantear —al margen la necesaria adhesión al Convenio-, el intento de articulación entre ambos Tribunales a fin de evitar la disparidad de criterios y la desarticulación entre dos instancias paralelas de tutela de los derechos, quizá convirtiendo al Tribunal de Estrasburgo en la última instancia de defensa de los derechos contra las vulneraciones provenientes de actos u omisiones de los Estados o de las propias instituciones de la Unión Europea ${ }^{62}$; aunque una objeción a tener en cuenta podrían ser los prejuicios soberanistas estatales, no admitiéndose que las instituciones comunitarias puedan ser "juzgadas" por una organización en la que se integran Estados no comunitarios, y que se vería afectada en su autonomía e independencia.

\section{LA TUTELA DE LOS DERECHOS EN LOS ESTADOS DESCENTRALIZADOS. ESPECIAL REFERENCIA AL PAPEL DE LOS ESTATUTOS DE AUTONOMÍA EN EL MARCO DE LA CONSTITUCIÓN ESPAÑOLA DE 1978}

De todos es sabido que determinados Estados compuestos (EE.UU., Suiza, Alemania, y recientemente Italia), contemplan la posibilidad de que las entidades políticamente descentralizadas regulen, en sus Estatutos y/o en sus Constituciones el régimen jurídico de los derechos y libertades. Así pues, en el ámbito del Derecho Comparado son diversos los ejemplos de Estados compuestos en los que junto a una relación de derechos fundamentales contenidos en la Constitución estatal se incluyen derechos en las cartas constitucionales de los Estados miembros. Incluso puede afirmarse que algunas declaraciones son anteriores a la Declaración federal, tal y como sucede en

61 A tal efecto, dispone el art. 6 párrafo primero del Tratado de la Unión Europea, que la Unión se basa en los principios de libertad y democracia y en el respeto de los derechos y del Estado de Derecho; por su parte, en el párrafo segundo se indica que la Unión respetará los derechos tal y como se garantizan en el Convenio de Roma, y tal y como resultan de las tradiciones constitucionales de los Estados miembros. Este precepto ha de conjugarse con el art. 49 del Tratado de la Unión, que señala que cualquier Estado que respete los principios proclamados en el art. 6.1 podrá solicitar su ingreso en la Unión Europea, criterio que fue delimitado además en la reunión de Jefes de Gobierno en Copenhague en 1993, disponiéndose que los Estados miembros deberían acreditar tener instituciones estables que garanticen los derechos. De ello resulta el fuerte compromiso que han de mostrar los Estados en el respeto a los derechos, a cuyo efecto la adhesión de éstos al Convenio de Roma constituye un elemento clave para evaluar el ingreso en la Unión, a pesar de que, formalmente, no se "exige" acreditar dicha adhesión.

62 BIGLiNO CAMPOS, P., "De qué hablamos en Europa cuando hablamos de Derechos Fundamentales", Revista de Estudios Políticos, n 97, 1997, pp. 95 ss. 
Suiza donde el Tribunal Constitucional, antes de la reforma de la Constitución, utilizaba los derechos reconocidos en las Cartas fundamentales de cada cantón como "base" de los correspondientes derechos federales. Por su parte, en Alemania, el art. 1.3 señala que los derechos federales tienen efecto directamente obligatorio respecto de los órganos de los Länders y sobre el derecho constitucional de cada uno de ellos ${ }^{63}$.

Los primitivos Estatutos de Autonomía contenían una cláusula general y algunas menciones singulares a determinados derechos y libertades, así como una serie de principios rectores o básicos de sus instituciones autonómicas. Sin embargo, los actuales procesos de reforma estatutaria aprobados han generalizado - con mayor o menor extensión, con mejor o peor técnica jurídica, con una regulación plenamente normativa o programática-, el reconocimiento de toda una serie de derechos y libertades, lo cual no deja de plantear importantes problemas jurídicos.

Junto a ello hay que destacar la diversidad de la regulación normativa ofrecida por las reformas estatutarias. En efecto, las categorías jurídicas utilizadas no son siempre las mismas, produciéndose una mezcla entre derechos estatutarios y principios rectores. Al propio tiempo hay que afirmar que difícilmente es posible proclamar la existencia de auténticos derechos subjetivos, pues estos únicamente adquirirán tal condición cuando sean desarrollados por el legislador autonómico, convirtiéndose únicamente en limites, y a la vez en mandatos, a la actuación de los poderes autonómicos. Como señala el Dictamen del Consejo Consultivo de Asturias, el Estatuto de Autonomía, a estos efectos, es una norma "dirigente", aunque una vez establecidos los contenidos estatutarios, y efectuada la intervención del legislador autonómico, la supresión o aminoración de estos derechos podría ser considerada como antiestatutaria y, por lo tanto, inconstitucional. Finalmente, muchos de estos derechos no son sino una reiteración de nuestra regulación constitucional, o de determinadas regulaciones de carácter internacional, produciéndose, todo lo más, una concreción de estos derechos. Es decir, resulta difícil afirmar que se creen derechos nuevos, siendo tan solo manifestaciones concretas de derechos fundamentales y constitucionales.

Asimismo, quisiéramos destacar que los Estatutos de Autonomía, más que pretender ser una norma de emulación constitucional, lo que deben contener son auténticos mandatos normativos y no normas meramente programáticas. Su condición de norma jurídica y de norma institucional básica de su respectiva Comunidad Autónoma así parece exigirlo. Es decir, no se trata de elaborar una amplia declaración de derechos y libertades, sino de insistir en su calidad acentuando, dentro de los límites constitucionales, las prestaciones de los poderes públicos autonómicos.

63 APARICIO, M.A., (ed): Derechos y libertades en los estados compuestos, Dykinson, Barcelona, 2005, y las diversas aportaciones en esta obra de E. ROSSI, J.M. CASTELLA ANDREU, M. HARTWIG, M. VERDUSSEN, U. THALMAN, A. TARR, J. WOEHRLING, A. GAMPER. Asimismo, ROLLA, G., (comp. ): Lo svilupo dei diritti fondamentali in Canada, Giuffrè, Milano, 2000. 


\section{LA CONSTITUCIONALIDAD DEL RECONOCIMIENTO DE DERECHOS EN LOS Estatutos DE Autonomía}

Aunque no figuren como uno de los contenidos mínimos del art. 147.2, no parece existir inconveniente alguno para que puedan ser calificados como un contenido, adicional e inherente, a los Estatutos, tanto por la función constitucional que estos desempeñan, como por su relación directa con las competencias asumidas, no pudiendo implicar nunca una alteración del régimen de distribución competencial ni la creación de tipos competenciales nuevos. Todo ello sin olvidar que el reconocimiento estatutario de los derechos y libertades actúa como limite a la acción de los poderes públicos autonómicos ${ }^{64}$. Al propio tiempo, hay que señalar que la regulación estatutaria de los derechos implica necesariamente una limitación sobre el modo en que se han de ejercer las competencias. Por otro lado, carecería de sentido negar esta posibilidad a los estatutos cuando el legislador autonómico ya lo ha hecho a través de diversas leyes sectoriales ${ }^{65}$.

Así pues, y con carácter general, no parecen existir problemas de inconstitucionalidad en la existencia de una carta de derechos y libertades en los Estatutos de Autonomía, pues el legislador autonómico se encuentra tan facultado como el estatal para colmar la reserva de ley ordinaria en esta materia, siempre y cuando actué dentro del marco de sus competencias y respeten los límites constitucionales establecidos ${ }^{66}$. Por otro lado, la inclusión de una tabla de derechos contribuye a reafirmar el sentido político de la autonomía de las Comunidades Autónomas, sin olvidar la pretensión de algunos Estatutos de asimilarse a una Constitución, o de tener, al menos, una apariencia de Constitución. Ahora bien, la existencia en los Estatutos de una tabla derechos y libertades, en buena lógica jurídica, no puede significar un incremento del au-

64 Esta es una de las razones que, para avalar su legitimidad constitucional, proporcionó el Dictamen del Consejo Consultivo de Cataluña: lo que se hace es imponer reglas, condiciones y garantías a la Generalidad y por lo tanto actúa como un límite al ejercicio de sus competencias, de manera que se asegure de la manera más amplia posible la dignidad de la persona y el libre desarrollo de su personalidad.. Por su parte, el Dictamen del Consejo Consultivo de Galicia señala que "los derechos fundamentales (...) se erigen, además, en criterio de distribución de la potestad legislativa constituida".

65 GARCÍA ÁlVAREZ, M., y GARCíA LÓPEZ, R., "Los derechos sociales en la reforma de los Estatutos de autonomía" en el libro colectivo La reforma de los Estatutos de Autonomía, Revista Jurídica de Castilla y León, Junta de Castilla y León, 2003; SÁNCHEZ FÉRRIZ, R., "Derechos sociales y Comunidades Autónomas: los márgenes de las políticas autonómicas" en el libro colectivo El estado autonómico. Integración, solidaridad y diversidad, INAP, Madrid, 2005.

66 Cfr. BRAGE, J., "Algunas breves consideraciones sobre los limites a los derechos fundamentales en el Estado autonómico", y A. BARRERO ORTEGA: Derechos fundamentales: inalienables, imprescriptibles, ¿indivisibles?", ambos en RUIZ RICO, G. (Coord.), La reforma de los Estatutos de Autonomía, Tirant Lo Blanc, Valencia, 2006; LUCAS MURILLO, E., "Delimitación de la competencia autonómica para la regulación de los derechos fundamentales", Revista de Derecho Político, núm. 46, 1999; BARNES, J., Problemas y perspectivas del articulo 149.1.1. CE, Institut d'Estudis Autonòmics, Barcelona, 2004. 
togobierno, pues no supone un plus competencial alguno. Otra cosa es que acreciente la función constitucional del Estatuto de Autonomía, que dejan de ser mera normas institucionales y de delimitación de las competencias y de los aspectos identitarios y simbólicos de la propia Comunidad Autónoma. Y, lo que a nuestro juicio debe ser más importante, la posibilidad de que los ciudadanos sean titulares de nuevos derechos subjetivos y de nuevas prestaciones exigibles a los poderes públicos autonómicos ${ }^{67}$.

Lo cierto es que el ejercicio de muchos de estos derechos, especialmente los de carácter económico y social, necesita de la interposición del legislador autonómico, pues la reserva de ley constitucionalmente establecida no es exclusivamente a favor de la ley estatal, pudiendo hablarse de una reserva de ley compartida o fragmentada. En caso contrario, si se produjera una identificación con la ley estatal, se vaciarían de contenido muchas competencias autonómicas. La reserva solo puede identificarse con la ley estatal cuando afecte a las condiciones básicas que garanticen la igualdad de todos los españoles en el ejercicio de sus derechos y en el cumplimiento de los deberes constitucionales, pudiendo las Comunidades Autónomas, cuyos Estatutos le atribuyan competencia legislativa sobre una materia determinada, proceder a una regulación del ejercicio de los derechos constitucionalmente garantizados (STC 37/1981).

Por otro lado, son precisamente los entes descentralizados los legitimados competencialmente para realizar toda una serie de políticas públicas en directa relación con los derechos fundamentales. Y es que, aunque la internacionalización de los derechos y libertades supuso un paso importante, su territorialización no debe ser entendida como un paso hacia atrás, siempre que mantenga y guarde la coherencia de todo el ordenamiento jurídico. Así ocurre en muchas leyes autonómicas relativas al ejercicio de derechos como la educación o la salud. Si el legislador autonómico es competente, e incluso, necesario, mayormente lo será el legislador estatutario. Por otro lado, resulta difícil imaginar una competencia autonómica que no este relacionada con el ejercicio de algún derecho y libertad, que sea ajena a los derechos fundamentales. Y finalmente, a nuestro juicio no resulta fácil determinar cuales sean los derechos sobre los que no cabe alguna competencia por parte de las Comunidades Autónomas, aunque la postura mayoritaria se inclina porque los estatutos solo deben incluir los derechos sociales. A este respecto, nuestra jurisprudencia ha reconocido la posibilidad de limitar el ejercicio de determinados derechos sociales (propiedad privada, libertad de empresa...), siempre que se posean los títulos competenciales al respecto.

67 Frente a estos planteamientos, el recurso de inconstitucionalidad interpuesto por el Defensor del Pueblo contra el Estatuto de Cataluña considera que la inclusión de una Declaración de derechos y libertades viola el principio de reserva estatutaria, pues es una competencia exclusiva del legislador constituyente, correspondiendo únicamente al legislador ordinario el desarrollo y ejercicio de los mismos. Para el recurrente, el estatuto es solo una norma organizativa y delimitación competencial, pues el poder constituyente no ha solicitado su intervención en el campo de los derechos fundamentales, sino tan solo la del legislador estatal. 


\section{Problemas jurídicos planteados}

a) El respeto a los límites constitucionales establecidos

Los Estatutos de Autonomía, en su regulación normativa deben de respetar el principio de reserva de ley orgánica del art. 81.1 CE, que afecta al "desarrollo de los derechos fundamentales y libertades publicas" pero que no se refiere a todo su contenido, pues la expresión "desarrollo" hay que ponerla en relación con las expresiones "contenido esencial" y "regulación del ejercicio" del art. 53.1 y "afectación" del art. 86.1.

A este respecto, existe una abundante jurisprudencia constitucional que es expresiva de su propia evolución. Así, la STC 25/1981, de 14 de julio, señala que "Los derechos fundamentales son asi un patrimonio común de los ciudadanos individual y colectivamente, constitutivos del ordenamiento jurídico cuya vigencia a todos atañe por igual”. Más adelante el Tribunal realiza una modulación de su doctrina en las SSTC 37/1981, 6/1982, 76/1983, 164/1986, señalando que el art. 139.1. "no puede ser entendido en modo alguno como una rigurosa y monolítica uniformidad del ordenamiento de la que resulte que, en igualdad de circunstancias, en cualquier parte del territorio nacional, se tienen los mismos derechos y obligaciones" (STC 37/1981, también la STC 14/1998). Y es que dicho precepto contiene un mandato de igualdad de todos los españoles ante cada ordenamiento autonómico, no resultando viable comparar entre sí a individuos sometidos a distintos ordenamientos. Por ello, señala la STC 37/1987 que "El principio de igualdad no impone que todas las Comunidades Autónomas ostenten las mismas competencias, ni menos aun, que tengan que ejercerlas de una manera o con un contenido y unos resultados idénticos o semejantes (...)”. Esta doctrina se mantiene en las sentencias 61/1997 y 173/1998, donde se señala que el art. 149.1.1 CE no puede operar como un título horizontal, capaz de introducirse en cualquier materia o sector del ordenamiento jurídico, no agotando el régimen jurídico del derecho en cuestión, pues el Estado esta únicamente habilitado para regular el contenido primario, las facultades elementales y sus límites esenciales (SSTC 103/1999, $164 / 2001,54 / 2002$ y $178 / 2004)$.

Es decir, frente al contenido abstracto proclamado en la Constitución, la norma sujeta a reserva de ley orgánica debe desarrollar su contenido concreto, que debe ser esencial de acuerdo con lo dispuesto por el art. 53.1. Ello plantea el problema de si el desarrollo del art. 81 coincide o no con la regulación del ejercicio de que habla en el art. 53.1, cuestión que hay que resolver en función de cada derecho y libertad, aunque a priori, tengan que coincidir necesariamente. Uno y otro, el desarrollo y la regulación del ejercicio, suponen una afectación del derecho y libertad. Ahora bien, el ámbito de la reserva de ley orgánica no es coextensivo al de las competencias atribuidas al Estado cuyo alcance, por otro lado, debe cohonestarse con los preceptos integrantes del bloque de constitucionalidad. Es decir, al Estado le corresponde la regulación de los aspectos esenciales, el desarrollo directo del de- 
recho fundamental considerado en abstracto, pudiendo corresponder al legislador ordinario, estatal o autonómico, la regulación de la materia sobre la que se proyecta el derecho. El problema planteado es si las Comunidades Autónomas pueden o no incidir sobre los derechos reservados a la Ley Orgáni$\mathrm{ca}$, siempre que se respete el contenido esencial de los derechos. La respuesta positiva no parece admitir grandes discusiones: el desarrollo por ley orgánica no agota el desarrollo del derecho en cuestión, cabiendo un desarrollo adicional por ley ordinaria estatal o por el legislador autonómico, según sea el ámbito competencial respectivo ${ }^{68}$.

\section{b) La naturaleza de los derechos estatutarios}

No estamos ante una cuestión baladí. En principio, se plantea el problema de si los Estatutos de Autonomía pueden reconocer derechos fundamentales distintos a los consagrados en la Constitución, y si nos encontramos en presencia de derechos de distinta naturaleza, contenido y significado. Por un lado, se encuentran las tesis doctrinales que señalan que los estatutos no pueden crear derechos fundamentales, limitándose su función a convertir un principio rector en un derecho subjetivo, a fin de obligar únicamente a los poderes públicos autonómicos. Otros sostienen la posibilidad de regular derechos constitucionales, añadiéndole nuevos contenidos que aumenten su ámbito, su eficacia y garantía. La Constitución no impide que las Comunidades Autónomas puedan convertir en derechos subjetivos los principios rectores de la política social y económica, que puedan ser exigidos ante los poderes públicos, y siempre que se deriven de un titulo competencial reconocido estatutariamente. En todo caso, parece lógico que la intervención de los poderes autonómicos, incluso en materia de derechos económicos y sociales, sea compatible con la intervención estatal ${ }^{69}$.

Del análisis de las diferentes reformas estatutarias aprobadas, es posible deducir que las declaraciones de derechos contienen derechos estatutarios, derechos de configuración legal y principios rectores de la política social y económica. Por otro lado, no todos ellos tienen la condición de auténticos derechos, siendo la mayoría de ellos principios rectores que vinculan a los po-

68 No ha de olvidarse que el Informe del Consejo de Estado sobre la reforma constitucional señala que no se puede prohibir que los estatutos otorguen a los ciudadanos derechos de los que no gozan otros habitantes de otra Comunidad Autónoma, pues ello impediría a todas las CCAA ir mas allá de lo que haya ido la Comunidad Autónoma que menos los garantiza. Lo que prohíbe es un tratamiento jurídico diferenciado entre los ciudadanos de cada Comunidad, reconociendo derechos a unos sí y a otros no. Otra cosa es que se entienda que los derechos de esta naturaleza han de ser los mismos en todo el territorio nacional e idénticos los servicios públicos que satisfagan las correspondientes prestaciones. Para ello, debería incorporarse expresamente a la Constitución una norma de este tipo.

69 Cfr. PÉREZ AYALA, A., "En torno al Estado social autonómico", El Estado autonómico. Integración, op. cit. 
deres públicos autonómicos. Es decir, únicamente adquirirán la condición de derechos subjetivos cuando se produzca la interposición del legislador autonómico a través del desarrollo de la correspondiente ley. Por otro lado, en no pocas ocasiones se trata de una simple reproducción de los preceptos constitucionales del Titulo I. Todo ello puede producir un importante desequilibrio, tal y como pone de relieve el Informe del Consejo Consultivo de Asturias que llega a calificar de "papel mojado" muchos de estos contenidos estatutarios, concluyendo que con ello se puede perder en "autonomía normativa" y que "por mas que se quiera engrosar un texto, un Estatuto de Autonomía no es una constitución de un estado miembro de una Federación".

Los contenidos de las reformas estatutarias emprendidas, junto a concomitancias notables, presentan diferencias sustanciales. Así, y a modo de ejemplo, el texto valenciano se diferencia del catalán por tres razones: «el texto valenciano regula en puridad y básicamente principios rectores, mas que derechos sensu stricto; segundo, el núcleo esencial de regulación de los derechos y libertades valencianos sigue hallándose, por expresa remisión del texto estatutario, en la Constitución y en los textos internacionales en la materia; tercero, el estatuto valenciano no prevé, como si hace en cambio el catalán, un mecanismo especifico de garantía de los derechos y libertades, que actúa en yuxtaposición al incluido en la Constitución ${ }^{70}$.

A priori parece posible sostener que los Estatutos de Autonomía no pueden contener derechos fundamentales, pues estos están sujetos al principio de reserva de ley orgánica, sin que pueda sostenerse a este respecto la tesis de que, al ser un Estatuto de Autonomía una ley orgánica, este principio de reserva de estaría garantizado. Sin embargo esta reserva solo afecta al "desarrollo" de los mismos, que, según nuestro Tribunal Constitucional (SSTC 101/1991, 292/2000 y 53/2002), tiene que ser un desarrollo "directo", que afecte al contenido sustancial del derecho en cuestión y a la determinación de sus limites externos y internos, las relaciones del mismo con terceros privados, las garantías fundamentales frente a los poderes públicos, pudiendo regularse por el legislador ordinario, estatal u autonómico, y las cuestiones referentes a la concreción del tiempo, modo y lugar del ejercicio del derecho. No obstante, resulta aconsejable que los Estatutos hagan una referencia a los derechos, fundamentales establecidos en el texto constitucional y otras Declaraciones Internacionales, como manifestación de la sujeción de los poderes autonómicos a los mismos.

En cuanto a los demás derechos constitucionales, su desarrollo ha de efectuarse a través de ley ordinaria estatal. Es decir, ante la redacción del art. 53.1, la regulación del ejercicio de estos derechos, es decir, la determinación de los requisitos de modo, tiempo y lugar de la realización del derecho. En principio, es posible sostener que, al igual que la interpretación ofrecida por el Tri-

70 Así lo entiende el Informe del Letrado de la Comisión General del Senado, GARCIA MEXÍA, P., de 11 de abril del 2006, al Proyecto de Reforma del Estatuto de Cataluña. 
bunal Constitucional en el sentido de que la reserva de ley orgánica incluye la regulación de lo indispensable y necesario para el ejercicio del derecho (STC 22/1986), también la reserva de la ley ordinaria estatal tendría este alcance. Sin embargo, el Tribunal ha entendido que esta reserva de ley ordinaria no tiene que ser necesariamente estatal, pudiendo también tener la condición de ley autonómica, debiendo únicamente emanar de las Cortes Generales, "cuando afecte a las condiciones básicas que garanticen la igualdad de todos los españoles en el ejercicio de los derechos y en el cumplimiento de los deberes constitucionales" (STC 37/1981). Es decir cuando entre en juego el art. 149.1.1. CE. Cuando no se vean afectadas las condiciones básicas del ejercicio del derecho, la reserva de ley puede permitir la intervención del legislador autonómico, siempre que sus Estatutos le atribuyan competencia legislativa sobre una materia cuya regulación implique necesariamente un desarrollo del ejercicio de derechos constitucionalmente garantizados.

Junto al principio formal de reserva de ley, orgánica u ordinaria estatal, la actuación legislativa de la Comunidad Autónoma está supeditada a la asunción de potestades legislativas en la materia afectada. A este respecto, la STC 75/1990 exigirá que la actuación de las Comunidades Autónomas no cree rupturas, divergencias irrazonables y desproporcionadas según la STC 48/1988, en las condiciones básicas de igualdad de todos los españoles. Es decir, se debe producir una cierta uniformidad, que no identidad, siendo posible la diversidad, inherente al concepto de autonomía.

Las regulaciones estatutarias contienen derechos de configuración legal o simples principios rectores de la política social y económica. Los primeros normalmente han sido objeto de desarrollo por el legislador estatal a través de legislaciones básicas sectoriales. En este caso, los derechos existen con independencia de su incorporación al Estatuto. Únicamente, en el caso de su desaparición en la legislación básica estatal podría sostenerse la perduración de los mismos como auténticos derechos estatutarios. Por otro lado, muchos de estos derechos ya habían sido regulados por el legislador autonómico, produciéndose ahora su incorporación al estatuto. Casi todos son derechos sociales o prestacionales, debiendo producirse una actuación, además de los correspondientes recursos económicos, del correspondiente legislador autonómico. Es decir, su interposición se convierte en necesaria para su plena eficacia y para la determinación del alcance concreto de la prestación que conlleva. En cualquier caso, ello exige un análisis particular de los derechos, pudiendo encontrarse en muchas ocasiones más principios rectores que propiamente derechos sociales. Y todo ello sin dejar de advertir que con estas declaraciones aumenta el valor político del Estatuto y se acentúa su carácter simbólico.

Directamente relacionada con el tema de la naturaleza de los derechos estatutarios, se encuentra la posibilidad o no del establecimiento de un sistema de garantías propio, diferente, alternativo o sucesivo al establecido por nuestra Constitución. A tal efecto, hay que recordar que el Tribunal Constitucional alemán ha reiterado que las garantías excesivas en la protección de los dere- 
chos y libertades, si llegaran a ser incompatibles con la legislación federal, esta última es la que ha de prevalecer. Todo ello, sin perjuicio de la "doble seguridad para los derechos del pueblo" de la que hablara ya MADISON en el Federalista. Será posible un sistema estatutario de garantías siempre que no se invadan las competencias estatales, limitándose con ello, de modo muy notable, la posibilidad de establecer garantías jurisdiccionales, aunque no extrajudiciales (como puede ser la arbitral), tal y como hacen diversos Estatutos. Al Estado le corresponde en exclusiva la legislación procesal y penal y, como señala la STC $47 / 2004$ ha de salvaguardarse la uniformidad de los instrumentos jurisdiccionales (igualmente el Dictamen del Consejo Consultivo de Galicia, que se opone a la creación de una Sala de protección en los Tribunales Superiores de Justicia).

Diversos preceptos estatutarios encomiendan a los Tribunales Superiores de Justicia la tutela de los derechos reconocidos en el respectivo Estatuto de Autonomía. El tema puede plantear importantes problemas jurídicos, como son los referentes a las normas procesales aplicables, en el sentido de si serán las de carácter general, configurando aquellos Tribunales la última instancia o, por el contrario, se pueden dictar normas procesales por cada Comunidad Autónoma ${ }^{71}$. A nuestro juicio el establecimiento de garantías jurisdiccionales de los derechos estatutarios no es posible a través de los Estatutos de Autonomía. Recordemos que la STC 47/2004 puso de relieve que la atribución al Estado de la competencia exclusiva sobre legislación procesal responde a la necesidad de salvaguardar la uniformidad de los instrumentos jurisdiccionales. Es decir, la protección jurisdiccional de los derechos estatutarios es competencia del legislador estatal. Ello no impide que, en vía administrativa, puedan establecerse garantías adicionales cuando los derechos estatutarios entren en juego, siempre que se respeten las competencias estatales. Incluso es posible la existencia de una "autoridad moral del arbitraje", a que se refiere el Dictamen del Consejo Consultivo de Galicia. Pero es cierto que otra parte de la doctrina $^{72}$ mantiene, con respecto a esta materia en el Estatuto Catalán, por ejemplo, que la propuesta de reforma de establecer un recurso ante el Tribunal Superior de Justicia de Cataluña parece promover, en cuanto a la organización judicial se refiere, una descentralización o desconcentración del Poder Judicial, reforzando su posición y sin perjuicio de la funcionalidad del recurso de amparo, como instrumento extraordinario del Tribunal Constitucional como garantía de los derechos. Asimismo, esta doctrina añade que la intro-

71 A este respecto, resulta difícil admitir la constitucionalidad del art. 38 del Estatuto Catalán tal y como se indica en el recurso presentado por el Partido Popular, pues supone una alteración del sistema establecido en el art. 53.2. CE, el cual resulta indisponible para las CCAA, siendo una competencia exclusiva estatal la concreción procesal de dichas garantías. Todo ello sin olvidar que este mandato al legislador estatal, de generalizarse en todos los Estatutos, supondría la creación de una diversidad radical incompatible con el sistema judicial diseñado por la Constitución.

72 FERRERES COMELla, V., BIGLINO CAMPOS, P., y CARRILlO, M., Derechos, deberes y principios en el nuevo Estatuto de Autonomía de Cataluña, Centro de Estudios Políticos y Constitucionales, Madrid, 2006. 
ducción de una declaración de derechos en el Estatuto de Cataluña, va a producir que sí la Comunidad Autónoma sea la que se encargue de desarrollar la mayoría de los derechos reconocidos en dicha declaración, por tanto parece lógico establecer un recurso con sede natural para la tutela y protección de dichos derechos. Aún así, habrá que esperar la modificación de la Ley Orgánica del Poder Judicial.

Finalmente, si hablamos de la tutela y protección de los derechos en el ámbito autonómico hay también que mencionar al Consejo de Garantías Estatutarias, propuesto en el Estatuto Catalán. Dicho estatuto añade una competencia a este Consejo, que es donde radica la novedad de este órgano (ya que esta competencia es la que marcaría la diferencia con el actual Consejo Consultivo de Cataluña), que es la del carácter vinculante de sus dictámenes cuando se trate de proyectos de ley y de proposiciones del Parlamento que se encarguen de desarrollar a los derechos reconocidos en el Estatuto Catalán. Parte de la doctrina sostiene que esta nueva competencia no resulta inconstitucional $^{73}$ ya que dicha competencia es anterior a la aprobación de las leyes en el Parlamento y por tanto no interfiere posteriormente con las competencias del Tribunal Constitucional.

\section{A MODO DE CONCLUSIÓN}

La regulación en los Estatutos de Autonomía (unas más amplias, como las de Cataluña y Andalucía; otras más restringidas, como las de Valencia, Baleares y Aragón) de una auténtica carta de derechos, aparte de suponer un intento de asimilación de los Estatutos a la Constitución, no parece plantear problemas de constitucionalidad, aunque sí de técnica jurídica, pues puede resultar que muchas normas estatutarias tengan un carácter meramente programático. Todo ello siempre que respeten los límites del principio de reserva de ley orgánica del art. $81 \mathrm{CE}$, el principio de igualdad de los arts. 139 y 149.1.1. CE, la imposibilidad de que ello suponga la asunción de nuevas competencias y la invasión de las competencias estatales, así como la imposibilidad de establecer nuevas garantías jurisdiccionales ni la imposición de mandatos al legislador estatal.

Incluso, es posible sostener, siguiendo las propuestas efectuadas por el Informe del Consejo Consultivo de Asturias, la necesariedad y adecuación de una Tabla de Derechos en los Estatutos de Autonomía, pero hay que precisar jurídicamente su contenido, evitando reiteraciones innecesarias y atendiendo a la selección de la calidad de los derechos en cuestión. El necesario respeto a la Declaración de Derechos constitucionalmente establecida, así como a las

73 Ibidem. A nuestro criterio, la inconstitucionalidad del precepto estatutario también puede sostenerse desde los postulados del Derecho Parlamentario, al introducir un trámite procedimental en el procedimiento legislativo que puede atentar, por su carácter vinculante y no meramente preceptivo, al principio de autonomía de las Cámaras. 
contenidas en los Tratados Internacionales, y la autonomía de los poderes públicos autonómicos, se convierten en criterios a tener en cuenta. Lo importante no es elaborar una Tabla de Derechos con la finalidad exclusiva de asimilar los Estatutos a una Constitución, sino regular, a nivel estatutario, cual es el grado de intervención de los poderes autonómicos para hacer efectivo un sistema real de prestaciones publicas en orden a un ejercicio efectivo de los derechos y libertades para los ciudadanos.

\section{LAS CARTAS LOCALES DE DERECHOS: HACIA UNA TUTELA "DE PROXIMIDAD" DE LOS DERECHOS}

De la evolución y desarrollo de los derechos no pueden permanecer ajenos las propias ciudades: ningún otro ente se encuentra más cercano al ciudadano, y ningún otro organismo es capaz de estar más atento a las necesidades, a los derechos de las personas; en definitiva, una democracia de proximidad. Por ello es indudable que los entes locales han de contribuir a la eficacia y plenitud de las diversas generaciones de derechos y, en particular, de aquéllos en los que más directamente la ciudad tiene depositada su efectividad última.

El sistema de derechos es como un gran templo: con sus cimientos, sus cuatro columnas y un frontón, que recogen el preámbulo y los treinta artículos de la Declaración Universal. Todos los derechos son un conjunto inescindible: en la base los principio de libertad, igualdad, fraternidad y no discriminación; en la primera columna los derechos personales; en la segunda los derechos de los individuos en su relación con los demás; en la tercera los derechos espirituales, las libertades públicas y los derechos políticos; y en la cuarta los derechos económicos, sociales y culturales. Y por último en el frontón, los lazos que unen al individuo con la sociedad. Ahora bien, el templo está siempre en obras: en permanente construcción porque el proceso de consolidación de los derechos es largo y fatigoso, siempre en constante cambio, siempre ante nuevos retos ${ }^{74}$.

Los derechos han sido proclamados hasta la saciedad: a nivel internacional, supranacional, nacional, o autonómico..., pero aún así se ponen en evidencia ciertas deficiencias. Tal y como recordábamos en páginas anteriores, fundamentalmente los derechos económicos, sociales y culturales no han tenido un fuerte impulso a nivel internacional, y tampoco son desarrollados en plenitud en los textos constitucionales y, en particular, en la Constitución Española del 78. Y ello, por no citar el desarrollo y la necesaria concreción del art. 9.2 de la Constitución, que requiere de la atención particularizada a determinados grupos o colectivos coyuntural o estructuralmente desfavorecidos al objeto de al-

74 Cfr. Grupo de Investigación sobre "Los derechos humanos y la ciudad": http://www.ciudad-derechos.org/ (28 de octubre de 2006). Vid. la diversa documentación e informes realizados por este equipo investigador. 
canzar la igualdad material (conciliación de la vida profesional y familiar; atención a discapacitados, inmigración, etc.). Y por supuesto, con la labor que la ciudad es capaz de aportar a la eficacia de los derechos de solidaridad y a los de cuarta generación: incrementar la calidad de vida medioambiental y con ello el respeto de la vida privada y de la intimidad, así como el fomento de las nuevas tecnologías, o su singular y puntual —aunque no menos importantecontribución a los derechos de la información, entre otros...

Desde esta lógica ha de observarse la "Carta Europea de salvaguarda de los derechos en la Ciudad", firmada en Francia el 18 de mayo de 2000 a la que se han adherido diversas ciudades españolas, y cuyo origen se encuentra en el "Compromiso de Barcelona" - compromiso de las ciudades por los Derechos Humanos, 17 de octubre de 1998-. Sus objetivos fundamentales son el refuerzo de la todavía protección insuficiente otorgada por los restantes poderes públicos, y la consecución de una buena administración ligada, indudablemente, al respeto y garantía de los derechos humanos de todos sus habitantes, con la finalidad de promover la cohesión social y proteger a los más vulnerables. En definitiva, con el compromiso último de mejorar el bienestar y la calidad de vida de los ciudadanos adoptando, para ello, los postulados de la Carta Europea de Autonomía Local que promueve una administración municipal más eficaz y próxima al ciudadano.

La Carta recoge a continuación toda una serie de disposiciones generales relativas al derecho a la ciudad, el principio de igualdad de derechos y no discriminación, el derecho a la libertad cultural, lingüística y religiosa, la protección de colectivos y sectores más vulnerables, el deber de solidaridad, la cooperación municipal internacional, y el principio de subsidiariedad. Posteriormente se centra en los derechos civiles y políticos de la ciudadanía local (participación política, reunión, asociación y manifestación, protección de la vida privada y familiar, información), derechos económicos, sociales, culturales y ambientales de proximidad (derecho a los servicios públicos de protección social, educación, trabajo, cultura, vivienda, salud, medio ambiente, derecho a un urbanismo armonioso y sostenible, derecho a la circulación y tranquilidad en la ciudad, ocio, y consumidores), derechos relativos a la administración democrática local (eficacia de los servicios públicos, transparencia), para cerrar con un capítulo dedicado a los mecanismos de garantía de los derechos humanos de proximidad (administración de justicia, policía, prevención, mecanismos fiscales y presupuestarios $)^{75}$.

Con posterioridad, la Conferencia Europea de las Ciudades por la defensa de los Derechos Humanos (Nuremberg, 9-10 de diciembre de 2004), adoptaría toda una serie de conclusiones y recomendaciones en diversos ámbitos. En primer lugar, sobre los pasos a seguir para implementar la Carta: de un lado señalando el valor de la Carta —ético y moral, al tiempo que constituye un

75 VAQUER CABALlERÍA, M., "La Carta Europea de Salvaguarda de los Derechos Humanos en la Ciudad", Cuadernos de derecho local, núm. 2, 2003, pp. 130-145. 
acuerdo interadministrativo y transnacional-, y de otra parte, apuntando tres vías para la puesta en práctica de la carta (prevención y resolución de conflictos a través de una oficina de mediación, cooperación y ayuda mutua entre ciudades, y celebración de auditorias). En segundo lugar, centra su atención en la educación como mecanismo de expansión de los derechos. En tercer lugar, alude al fomento de la solidaridad y participación. En cuarto lugar, presta atención al derecho a la salud y a un medio ambiente saludable. Y por último, analiza el papel de las ciudades en la lucha contra el racismo y la discriminación.

\section{LOS DERECHOS EN LOS ÁMBITOS SECTORIALES PÚBLICOS Y PRIVADOS.}

Con esta expresión, "los derechos en el ámbito sectorial", queremos referirnos a determinadas regulaciones - a veces más bien una "autorregulación — - sobre los derechos y libertades tanto en el sector publico como en el sector privado, destinadas a incidir significativamente en el compromiso de transparencia y respeto humano en las relaciones entre ambas partes. Tan solo mencionaremos una serie de sectores ejemplificativos.

\section{El Ámbito púBlico}

A este respecto, y por lo que se refiere a nuestro ordenamiento jurídico, habría que mencionar, en primer lugar, la Carta de Derechos del Ciudadano ante la Administración de Justicia ${ }^{76}$. Resulta comúnmente aceptado que la idea de "Poder Judicial" no se agota en el ejercicio de la función jurisdiccional por parte de sus titulares. Junto a ello, existe también el concepto de "usuarios" y de "justiciables", en íntima relación con la consideración de la Justicia como servicio público.

La Carta regula de forma confusa toda una serie de derechos sin una adecuada sistematización, pudiendo afirmarse que "invade" campos propios de las leyes procesales; y no estableciendo, por otro lado, mecanismos adecuados de garantía. Su antecedente se encuentra en el Pacto de Estado para la Reforma de la Justicia, firmado el 28 de mayo del 2001 por el Gobierno, el PP y el PSOE, y cuya virtualidad, que no su denuncia, parece haberse difuminado tras las elecciones generales del 2004. Su finalidad, como expresamente se reconoce en la propia Carta no es otra que la "demanda con urgencia de una Justicia mas abierta que sea capaz de dar servicio a los ciudadanos con mayor agilidad, calidad y eficacia, incorporando para ello métodos de organización e instrumentos procesales más modernos y avanzados". Es decir, trata de poner 
al ciudadano en el centro de la Administración de Justicia, intentando que los principios de transparencia, información y atención adecuada, así como los derechos de los usuarios de la justicia, se conviertan en el núcleo auténtico de su actividad, en su norma de conducta.

Respecto a su fuerza jurídica, en principio parece posible afirmar que el instrumento a través del cual se aprueba, la proposición no de ley, no parece el más adecuado para regular derechos de los ciudadanos ante la Administración de Justicia, planteándose el problema de cual es su posición en el sistema de fuentes del Derecho que, por su propia naturaleza se caracteriza por huir de todo tipo de imprecisiones. En suma, el problema de esta proliferación de regulaciones sectoriales, que afectan a muchos ámbitos de la vida de los ciudadanos, no es otro que el de su eficacia, el de su exigibilidad y reclamación ante las instituciones garantes de los derechos, especialmente el poder judicial - al margen de su carácter simbólico e institucional- Sin duda alguna, la carta tiene una pretensión que va mas allá del instrumento jurídico con que ha sido concebida. Es aprobada por el Poder Legislativo, con el compromiso de que esta Carta/declaración vincule a los poderes públicos. No obstante, su vinculación está en función de cada uno de los derechos reconocidos, en la medida en que sea posible que estos derechos "declarativos" puedan ser ubicados en alguna norma jurídica que posibilite su efectividad ante los órganos jurisdiccionales. Ello puede conducir a una primera conclusión: algunos de estos derechos ya contaban con la previsión normativa correspondiente, mientras que otros necesitan aun el complemento de una norma jurídica que los ampare, sea esta una ley o un reglamento del propio Consejo General del Poder Judicial ${ }^{77}$.

Sobre el contenido de la Carta, se plantea el problema de que un derecho fundamental, como es el derecho a la tutela judicial efectiva, que goza de una posición constitucional relevante, necesite el complemento de esta Carta de derechos. Parece como si la garantía de este derecho fundamental presentase un resultado insatisfactorio, haciendo imposible, pese a las garantías judiciales establecidas, su plena vigencia porque el Poder Judicial no dispone de una organización administrativa eficaz que ofrezca un servicio publico a la altura del siglo XxI. Ciertamente, la cuestión es más compleja. Realmente, lo que pretende la Carta es situar a los ciudadanos, no como elemento pasivo sino como titular de una serie de derechos ante el entramado del poder judicial. La Carta insiste en el derecho a presentar las quejas y sugerencias ante el propio Juzgado o Tribunal, sus órganos de gobierno, las oficinas de atención al ciudadano, al CGPJ, al Ministerio de Justicia o ante las Administraciones de las Comunidades Autónomas, garantizando el ejercicio de este derecho por vía telemática. Asimismo, entiende que la coordinación es una

77 Así sucede, a modo de ejemplo, con el Reglamento 1/1998, de 2 de diciembre, que exige poner a disposición de todos los órganos de gobierno y las oficinas judiciales los formularios y materiales informativos, remitiendo los mismos a los interesados que lo soliciten. 
necesidad y una exigencia jurídica, tratando de evitar la distancia existente entre el ciudadano y la Administración de Justicia. Desde este planteamiento general, se pretende dar eficacia a los siguientes postulados: 1) Una justicia moderna, transparente y abierta a los ciudadanos. 2) Una justicia comprensible para los ciudadanos, evitando su carácter inaccesible. 3) Una Justicia responsable ante los ciudadanos. 4) Y una Justicia ágil y tecnológicamente avanzada.

Por otro lado, también en el ámbito público, y siguiendo la práctica de incorporar en el Gobierno del Estado las buenas prácticas del sector privado y las recomendaciones realizadas por organismos internacionales, el Ejecutivo aprobó un programa que incluía un Código con los principios éticos y de conducta a los que habrían de ajustar sus actuaciones. El objetivo básico es procurar que los altos cargos ejerzan su trabajo de acuerdo con las prestaciones que esperan los ciudadanos, con la finalidad de que éstos lleguen a depositar su confianza en las instituciones gubernativas y puedan controlar a los responsables públicos, como una democracia de nivel exige y al objeto último de que el ciudadano se sienta identificado con sus instituciones democráticas.

Fundamentalmente, en lo que al primero de los textos se refiere, por acuerdo del Consejo de Ministros de 18 de febrero de 2005, se aprobó el Código de Buen Gobierno de los miembros del Gobierno y de los altos cargos de la Administración General del Estado ${ }^{78}$. El Ejecutivo, siguiendo las recomendaciones de la Organización para la Cooperación y el Desarrollo Económicos (OCDE) y otras organizaciones, considero que era preciso explicitar en un documento escrito y público un código de responsabilidad, transparencia, honestidad y austeridad; en definitiva, toda una serie de postulados éticos que presidirían la acción del Ejecutivo ${ }^{79}$.

El Código, mostrándose en ocasiones reiterativo, estructura los principios que han de regir la actuación de los miembros del Gobierno y de los altos cargos de la Administración General del Estado, en tres apartados, referidos a los principios básicos (sometimiento a la Constitución, neutralidad, integridad, responsabilidad, etc.), éticos (promoción de derechos, prohibición de actitud discriminatoria, satisfacción de intereses generales, etc.), y de conducta (plena dedicación, ejemplaridad, austeridad, etc.). Tratándose de un "Código de autorregulación", cuyo principal obstáculo es su eficacia, se dispone efectivamente que a los efectos de su cumplimiento, el Consejo de Ministros examine el informe anual elevado por el Ministro de Administraciones Públicas, con la adopción de las medidas que se considere oportunas.

Por su parte, en el Programa se adjunta un Proyecto de Ley, actualmente convertido en Ley, destinado a modificar el actual régimen de incompatibili-

78 Orden APU/516/2005, de 3 de marzo (BOE, de 7 de marzo de 2005).

79 Vid. RODRÍGUEZ-ARANA MUÑOZ, J., El buen gobierno y la buena administración, Aranzadi, Pamplona, 2006. 
dades de los altos cargos de la Administración ${ }^{80}$, con los requisitos precisos para el nombramiento de los titulares de determinados órganos, entre ellos la obligación de comparecencia ante el Congreso de los Diputados. Se disponen, además, toda una serie de obligaciones para prevenir situaciones que originen conflictos de intereses; se consagra el principio de dedicación absoluta del alto cargo a su puesto público, limita las actividades que puedan perturbarla - eliminando la percepción de retribuciones por su participación en órganos rectores o Consejos de Administración de empresas con capital público-; o se refuerza el control sobre los intereses patrimoniales de los altos cargos y sus familiares — quedando prohibida una participación superior del 10\% en las empresas que entablen relaciones con la Administración (contratistas, subvenciones) - El proyecto establece, de otro lado, nuevas garantías en el desempeño de actividades privadas de los altos cargos una vez cesan como tales, con la finalidad de que la imparcialidad e independencia del cargo público no se vean afectadas durante el ejercicio del cargo público. Por último, se crea la Oficina de Conflictos de Intereses, y se refuerza el régimen sancionador.

En esta línea de ofrecer un funcionamiento de la Administración Pública transparente, eficaz, con una nueva regulación de los derechos de los empleados públicos que redunde finalmente en los derechos de los administrados y en el interés general, ha de concebirse la Ley $7 / 2007$, de 7 de abril, del Estatuto Básico del Empleado Público ${ }^{81}$. En su articulado, destaca su Título III, que acoge un catálogo de derechos —individuales (inamovilidad, progresión y promoción interna, formación continua, intimidad, etc.) y ejercidos colectivamente (sindicación, negociación colectiva, etc.) - y deberes (diligencia, objetividad, neutralidad, imparcialidad, etc.), así como un código de conducta inserto en la misma lógica del Código de Buen Gobierno al que nos hemos referido.

No obstante, a diferencia del Código de Buen Gobierno concebido desde la más pura técnica de la "autorregulación" que, en tanto soft law deposita fundamentalmente en la voluntad de sus destinatarios su realización práctica, el código de conducta de los empleados públicos se inserta en una auténtica norma jurídica con rango de ley, por lo que su capacidad aplicativa, grado de eficacia jurídica y posibilidad de sanción de las conductas contrarias a estas previsiones normativas, son en principio notablemente superiores.

Asimismo, en el ámbito de la Sanidad, cabría hacer referencia a la práctica instaurada de proclamar toda una serie de derechos y deberes de los pa-

80 Vid. MESEGUER YEBRA, J., "El proyecto de Ley de Conflictos de Intereses y el ámbito subjetivo de aplicación de la normativa reguladora de las incompatibilidades de los Altos Cargos de la Administración del Estado", Actualidad Administrativa, núm. 17, 2005, pp. 2052-2065.

$81 \mathrm{Al}$ respecto, CAVAS MARTÍNEZ, F., "Propuestas para un Estatuto Básico del Empleado Público" Aranzadi social, núm. 5, 2005; MARINA JALVO, B., "Consideraciones sobre el Informe para el Estudio y Preparación del Estatuto Básico del Empleado Público", Justicia administrativa: Revista de derecho administrativo, núm. 29, 2005, pp. 5-56. 
cientes. Resulta evidente que los avances de las ciencias médicas y de las tecnologías han modificado el concepto de "enfermo" con la aparición de una nueva relación más humanizada, de libertad y autonomía entre médicos y pacientes que se deben respeto recíproco, lo que ha llevado a centrar significativamente la atención en los derechos y deberes de que disponen éstos últimos.

La Ley General de Sanidad, de 25 de abril de 1986, modificada por la Ley 41/2002, de 14 de noviembre, básica reguladora de la Autonomía del Paciente y de derechos y obligaciones en materia de información y documentación clínica (arts. 9, 10 y 11) ${ }^{82}$, y la Ley 16/2003, de 28 de mayo, de cohesión y calidad del Sistema Nacional de Salud, partiendo del derecho que asiste a toda la ciudadanía a la protección de la salud y a la atención y prestaciones adecuadas - modificada por Ley 62/2003 - (art. 42 de la Constitución Española), consagran todo un elenco de derechos de los pacientes, de acuerdo con lo previsto en el Convenio de Oviedo (1997). De esta forma se alude al derecho del paciente a ser atendido con el máximo respeto; a disponer de una red de servicios adecuada, accesible y eficaz; a ser o no informado sobre su estado de salud; a negarse a una investigación médica; a renunciar a diagnósticos, tratamientos o procedimientos que no tengan carácter terapéutico; etc. Asimismo, respecto a los deberes, dispone el art. 11 de la Ley General de Sanidad que son obligaciones de los ciudadanos cumplir las prescripciones sanitarias; cuidar las instalaciones; responsabilizarse del uso adecuado de las prestaciones ofrecidas por el sistema; y firmar el documento de alta voluntaria en los casos de no aceptación del tratamiento ${ }^{83}$.

Esta generosa regulación se completa con lo previsto en las diversas leyes autonómicas que enriquecen la normativa estatal mediante la creación de específicas cartas de derechos y deberes, marcando la propia política autonómica en materia de sanidad. Incluso en ocasiones, mediante un desarrollo normativo con atención en específicos apartados, a los derechos que corresponderían, por determinadas circunstancias, a singulares colectivos (niños, mujeres, etc. $)^{84}$.

Al objeto de seguir ofreciendo ejemplos de esta regulación "sectorial" de los derechos de los ciudadanos, cabe detenerse en los llamados "derechos del

82 Vid. SEUBA TORREBLANCA, J.C., RAMOS GONZÁLEZ, S., "Derechos y obligaciones en materia de autonomía privada, información y documentación clínica", Indret, núm. 138, 2003. En http://www.indret.com/pdf/138 es.pdf (30 de octubre de 2006); DE LORENZO MONTERO, R., Derechos y obligaciones de los pacientes: análisis de la ley 41/2002, de 14 de noviembre, básica reguladora de autonomía de los pacientes y de los derechos de información y documentación clínica, Cólex, Madrid, 2003.

83 Vid. asimismo VAQUER CABAllería, M., PAlOMAR OlMEDA, A., PAREJO AlFONSO, L.J., (Coord.), La reforma del Sistema Nacional de Salud: cohesión, calidad y estatutos profesionales, Marcial Pons, Madrid, 2004.

84 Vid. los arts. 2 y 3 del Decreto 175/1989, de 18 de julio, por el que se aprueba la Carta de derechos y obligaciones de los pacientes y usuarios del servicio vasco de salud: derechos de los niños a estar siempre acompañados durante la hospitalización, a que ésta sea preferentemente diurna, etc. 
pasajero" aéreo, previstos con la finalidad de garantizar un elevado nivel de tutela de los usuarios de este medio al mismo tiempo que se procura que los transportistas aéreos desarrollen sus actividades en condiciones armonizadas dentro de este mercado liberalizado. La normativa de la Unión Europea, en particular el Reglamento (CE) núm. 261/2004 del Parlamento Europeo y del Consejo, de 11 de febrero de 2004, constituye la regulación de referencia sobre la que AENA (Aeropuertos Españoles y Navegación Aérea), ha elaborado un documento resumen ${ }^{85}$. En él se recogen los derechos de los pasajeros en casos de denegación de embarque y anulación de vuelo, y grandes retrasos (derecho a indemnización y a la prestación de asistencia: devolución del importe del billete, ofrecimiento de comida y bebida, alojamiento y medios de comunicación o transporte), supuestos de rotura, deterioro, pérdida o retraso de equipaje (reclamación de una indemnización), lesiones corporales o muerte en caso de accidente (indemnización con el derecho al abono de un anticipo para cubrir las necesidades económicas inmediatas), y viajes combinados (además de los derechos ya previstos, es posible la reclamación por daños al operador turístico si éste no prestare los servicios contratados).

\section{EL ÁMBITO PRIVADO}

También en este ámbito se pretende atender a las particulares circunstancias y reivindicaciones que demanda un colectivo en una situación determinada, profundizando en el respeto mutuo y buenas prácticas de empresas y clientes, y donde destaca fundamentalmente la técnica de la "autorregulación" efectuada desde el propio sector.

En efecto, mediante la denominación "ética y buen gobierno" — buen gobierno corporativo-, se alude a toda una serie de principios y buenas prácticas desarrolladas en el ámbito de la empresa privada destinadas a procurar mayores cotas de eficacia, agilidad, responsabilidad y transparencia en los gobiernos de las empresas, con el objetivo último de lograr mayor credibilidad y procurar una mejor defensa de los intereses de los accionistas, siempre al servicio del interés social. En definitiva, se trata de poner en evidencia que el ámbito privado no escapa de la necesidad de plasmar compromisos dirigidos a la consecución de un buen gobierno que redundará en los derechos de los usuarios y de los propios accionistas, siempre desde el marco de la libre autonomía de la voluntad, procurando altas cotas de corrección y racionalidad en el gobierno de las empresas.

Tal y como exponía el Informe "Olivencia", el Código de Buen Gobierno deducido del citado informe, formula recomendaciones que pretenden sintetizar medidas o prácticas de buen gobierno (...) No trata de proponer normas de Derecho objetivo, sino de ofrecer a la consideración de las sociedades destina-

85 Vid. toda esta documentación en http://www.aena.es (30 de octubre de 2006). 
tarias un catálogo de medidas que, en uso de la libre autonomía de la voluntad $y$ de la facultad de autorregulación que nuestro ordenamiento jurídico les reconoce, podrán adoptar en sus estatutos o reglas de funcionamiento orgánico."

El buen gobierno en España se inicia con la Comisión Olivencia (1998) ${ }^{86}$, al que seguirán con posterioridad las recomendaciones de la Comisión "Aldama" (2003), la Ley de Transparencia, la Orden ECO/3722/2003, y la Circular CNMV 1/2004. Recientemente, el Gobierno por acuerdo de 29 de julio de 2005, dispuso la creación de un Grupo de Trabajo que asesoría a la Comisión Nacional de Valores y que, al objeto de armonizar y actualizar las recomendaciones de los Informes "Olivencia" y "Aldama" finalmente, en fecha 19 de mayo de 2006, aprobó el "Código Unificado de Buen Gobierno", a tomar como referencia por las sociedades cotizadas en el momento de presentación de su Informe Anual de Gobierno Corporativo ${ }^{87}$.

Al margen de las prácticas de buen gobierno corporativo establecido para las sociedades cotizadas, en el ámbito privado debe hacerse referencia al marco para la defensa de los derechos de los clientes fijado por la Ley 26/1984, de 19 de julio, General de defensa de los consumidores y usuarios - al margen la normativa autonómica-, muestra de tutela de los denominados "intereses difusos" y cuyo artículo 2 dispone que son derechos básicos de los consumidores y usuarios la protección contra los riesgos que puedan afectar su salud o seguridad; la protección de sus legítimos intereses económicos y sociales; la indemnización o reparación de los daños y perjuicios sufridos; la información correcta sobre productos o servicios; la educación y divulgación; la participación en procedimientos y representación de intereses a través de asociaciones, agrupaciones o confederaciones de consumidores y usuarios legalmente constituidas; y la protección jurídica, administrativa y técnica en las situaciones de inferioridad, subordinación o indefensión ${ }^{88}$. Con el propósito de eliminar prácticas abusivas, ha sido aprobada recientemente la Ley 44/2006, de 29 de diciembre, de mejora de la protección de consumidores y usuarios, entre cuyas novedades más significativas se encuentra la prohibición del redondeo al alza en productos y servicios (incluidos los aparcamientos), facilita la resolución de los contratos de determinados servicios, obliga a las compañías aéreas a dar el precio completo de los billetes, y eli-

86 Este informe tiene su origen en el acuerdo adoptado en Consejo de Ministros de 28 de febrero de 1997, de crear una Comisión Especial para el estudio de un Código ético de los Consejos de Administración de las Sociedades.

87 Vid. toda la documentación en http://www.cnmv.es/index.htm (28 de octubre de 2006). En el orden internacional y en otros Estados, constituyen un referente el Informe Winter (UE 2002), el Informe Higgs (Reino Unido, 2003); el Informe Smith (Reino Unido, 2003); The Combined Code On Corporate Governance (Reino Unido, 2003); The Corporate Governance Of Listed Corporations (Francia, 2003); Final NYSE Corporate Governance Rules (Estados Unidos, 2003); The Dutch Corporate Governance Code: Tabaksblat Committee (Holanda, 2003); OECD Principles of Corporate Governance (2004); y Recommendations On The Role Of (Independent) Non-Executive Or Supervisory Directors (Comisión Europea, 2004).

88 Vid. LLAMAS POMBO, E., Ley general para la defensa de los consumidores y usuarios: $\mathrm{Co}$ mentarios y jurisprudencia de la ley veinte años después, La Ley, Madrid, 2005. 
minar la obligación para el comprador de una vivienda de subrogarse en la hipoteca que pudiera tener contraída el vendedor.

A partir de este marco, es también cada vez más frecuente encontrar en las empresas privadas la tendencia a exponer los derechos de sus clientes: usuarios de los servicios de taxis ${ }^{89}$, empresas inmobiliarias ${ }^{90}$, colegios de abogados ${ }^{91}$, empresas telefónicas ${ }^{92}$, etc.; en cualquiera de estos casos con el compromiso adicional de fijar los derechos que ostentan empresas y clientes en las relaciones que entablen y lograr así una mayor transparencia, respeto mutuo y fiabilidad.

\section{UNA NOVEDAD EN LA TUTELA "MULTILEVEL" DE LOS DERECHOS: LA PROFUNDIZACIÓN EN LOS DEBERES DE LA CIUDADANÍA}

Frente al generoso y habitual reconocimiento de derechos de las personas, más extraño resulta hallar auténticos catálogos y declaraciones de deberes. De hecho, bastante escueta es la Constitución del 78 - deberes militares, tributarios y alguna referencia a los laborales, deberes educativos de los padres, o la obligación cívica que deriva del derecho de sufragio-, aunque quizá mayores perspectivas se abren ahora con las recientes reformas estatutarias o la novedosa técnica de las Cartas Locales. A esta escasa atención a los deberes puede haber contribuido la idea relativamente extendida según la cual los deberes se deducirían, a posteriori, del reconocimiento de los derechos, en la medida en que uno ha de observar respeto hacia los derechos de los demás; pero incluso, teniendo en cuenta que los deberes se desprenden de la propia convivencia social y democrática que demanda respeto en las relaciones interciudadanas.

Partiendo del concepto de deber jurídico, concebido como "la posición desventajosa de un sujeto al cual una norma jurídica imperativa le impone un determinado comportamiento frente a otros sujetos, quienes como consecuencia, se encuentran habilitados para ejercer una pretensión ${ }^{93}$, parece exis-

89 Los taxis en la ciudad de Barcelona incorporan una tarjeta adhesiva en varios idiomas en la que constan diversos derechos como elección del recorrido, vehículo limpio y conductor aseado, elección y graduación del volumen de sonido y temperatura interior, etc. Cfr. http://bcnweb2.bcn.es:8885/taxi/usuaricast/serveiusu.html (30/10/2006).

90 A título de ejemplo, http://www.fuertehoteles.com/agc/residencial/calaceite/922_es.asp $(30 / 10 / 2006)$

91 Como expresan diversas cartas adoptadas por Colegios de Abogados (a título de ejemplo, el Colegio del Tirol-http://insderpriserver.juri.ucv.ve/Carta $\% 20$ sobre $\% 201$ os $\% 20$ Derechos $\% 20$ del $\%$ 20Cliente.doc (30/10/2006): el derecho a la absoluta discreción de su abogado; a la confidencialidad; etc.

92 Vid.: http://www.entelpcs.cl/derechos/derechos_clientes.iws?IDP=\&IDPa2b= (30/10/2006): dispone esta empresa el derecho de sus usuarios a ser tratados de forma respetuosa, consistente y confiable; a ser informado y atendido por sus canales de atención; a recibir solución a sus problemas; a activar, desactivar y bloquear servicios; etc.

93 BIASCO, E., "Introducción al estudio de los deberes constitucionales. El principio de so- 
tir de todos modos un cierto consenso en torno a la idea de que los deberes pueden o no estar conectados con el ejercicio de otros derechos, e incluso que en ocasiones pueden derivarse de la necesidad de cumplimiento de intereses generales ${ }^{94}$.

Los deberes encontraron mención explícita en la Declaración Americana de Derechos y Deberes Humanos y, con posterioridad, aunque en un modo más difuso, en la Declaración Universal de Derechos Humanos de 1948 y en el Convenio de Roma de 1950, y con una mención explícita en un capítulo, en la Carta Africana de los derechos de los hombres y de los pueblos, en la Convención Americana de Derechos Humanos ${ }^{95}$. Por otro lado, la parte II de la Constitución Europea, no contiene un apartado específico a los deberes, limitándose su Preámbulo a señalar que "El disfrute de tales derechos conlleva responsabilidades y deberes tanto respecto de los demás como de la comunidad bumana y de las generaciones futuras".

Centrando nuestra atención en los deberes dirigidos a la ciudadanía, la Carta de Niza - y la Constitución Europea- ofrecen las pautas principales por las que ha discurrido y parece discurrir, el reconocimiento de dichos deberes: su configuración como «auténticos mecanismos propulsores del principio de solidaridad", es decir, imponiendo el cumplimiento de obligaciones de carácter común desde el punto de vista político, social, económico o familiar ${ }^{96}$. Tal y como parece estar ocurriendo con el actual proceso de reformas de los Estatutos de Autonomía, surge la tendencia a realizar proclamaciones de "situaciones de sujeción impuestas a los ciudadanos para tutelar un interés colectivo" o un interés "difuso" ${ }^{97}$ derivadas de principios y derechos de carácter prestacional y solidario, y que generan una clara corresponsabilidad social. Se trataría de postulados genéricos con cierta connotación metajurídica, cuyo carácter obligacional ha de ser concretado por la autoridad redactora de la norma de desarrollo, que será quien determine la exigibilidad de las conductas privadas, así como las oportunas sanciones deducibles de su incumpli-

lidaridad", en http://www.ccee.edu.uy/ensenian/catderpu/material/deberes\%20constitucionales.PDF (28/11/2006), p. 11. Asimismo, sobre los deberes jurídicos, GARZÓN VALDES, E., “Los deberes positivos generales y su fundamentación", Doxa. Cuadernos de filosofía del derecho, núm. 3, 1986, pp. 17-34; REDONDO, M.C., "El carácter práctico de los deberes jurídicos", Doxa. Cuadernos de filosofía del derecho, núm. 21, 1998, pp. 355-370.

94 Vid. en general, BOBBIO, N., "Derechos y deberes”, Letra Internacional, núm. 68, 2000, pp. 14-16.

95 DE LA FUENTE Y DE LA CALLE, M.J., “Los deberes del hombre, garantía de sus derechos fundamentales y de la convivencia social,, en BALADO, M., DE LA FUENTE, M.J., GARCÍA REGUEIRO, J.A. (Coords.), La declaración universal de los derechos humanos en su 50 aniversario, Madrid, 1999, pp. 117-130.

96 BIASCO, E., "Introducción al estudio de los deberes..." art. cit., pp. 3-4.

97 "Son intentos de vincular la conducta de los particulares que consisten fundamentalmente en un conjunto de prestaciones, de carácter personal las unas y patrimonial las otras, que los ciudadanos se encuentran obligados a efectuar, viniendo a completar de este modo, sin que tampoco pueda afirmarse que la idea de deber tenga que ser considerada como una contrapartida a la idea de derecho, las relaciones entre el Estado y la sociedad». Cfr. ÁLVAREZ CONDE, E., Curso de Derecho... op. cit., p. 582. 
miento, por lo que su destinatario principal pasan a ser los poderes públicos, que serán quienes los doten de eficacia inmediata y directa ${ }^{98}$. De este modo, la exigibilidad podrá ser directa (si pensamos en las obligaciones que se deducen del derecho al medio ambiente, por ejemplo), o bien indirecta (como en el caso de la renta de ciudadanía que consagran ahora diversos Estatutos para un determinado colectivo, y que va dirigida a erradicar la pobreza; teniendo en cuenta en tal sentido que la contribución de la sociedad no implica la personalización del deber, sino que éste posee un carácter colectivo y difuso). La consecuencia es, pues, la constatación de deberes de distinta naturaleza; y por ello, las sanciones derivadas de su incumplimiento sólo podrán explicitarse cuando los deberes constitucionales, estatutarios o incluso locales, se impongan con carácter directo y personal.

Los deberes se convierten en patrones de referencia para la formación de la voluntad de los poderes públicos, y fundamento básico para la creación $a$ posteriori de obligaciones específicas dotadas de un singular rango. Por ello, al tiempo que contribuyen a una satisfactoria educación cívica, podrán erigirse en límites razonables de los derechos y referentes importantes para la interpretación de las Cartas de Derechos por los operadores jurídicos y, en particular, por los jueces.

Desde el punto de vista de la tipología, cabría pues distinguir los deberes,

a) derivados de la personalidad humana: de respeto a los demás, a su libertad, integridad física y psíquica, dignidad; y, en general, a los derechos humanos;

b) de carácter social y para con los demás: derivados de una digna y adecuada convivencia social en un espacio común - ciudadanía solidaria y responsable - y, ante una extrema urgencia, el deber de colaboración; cooperación y asistencia con la seguridad social; uso responsable y solidario de prestaciones públicas y contribución al sostenimiento de gastos públicos; deberes de los padres hacia sus hijos, y de las personas hacia aquéllas otras que tienen a su cargo, y deberes recíprocos entre ambos; deberes educativos; colaboración con las Administraciones Electorales;

c) medioambientales: derivados del genérico deber de mantenimiento del medio ambiente — disfrute de recursos naturales, entorno equilibrado, sostenible y saludable-; respeto y contribución a una calidad de vida digna medioambiental (ruidos, inmisiones sonoras, etc.);

d) culturales: fomento de la cultura, respeto al patrimonio, deberes lingüísticos.

98 Cfr. BALAguer CALLejón, F., Manual de Derecho Constitucional, Tecnos, Madrid, 2005 (Tomo II), p. 316. 
ABSTRACT. The survey pretends an approach to the characteristic multilevel protection of rights throughly studied in the last times. Starting from previous considerations that should bighlight the value of fundamental rights in constitutionalism, we reach today a globalized world in which the benefits that citizens receive, as well as the juridical status, are exceeded by different levels of acknowledgement and protection in search of a perfect fitting. Therefore, the survey tackles such a problem tacking into account, on the one band, the complexity the new challewnges represent for the classical rights (biotechnology, collective rights, environment, etc.) and at the same time, on the other hand, noticing that the protection is "distributed" amongst many different and varied levels. If States and international organisms were until now the "natural" guarantors of rights, we must take into consideration, from this very moment, that the contribution of protection in the under state levels (regionalautonomous, local), but as well the emphasis that appears in the private field. Definitely, the multileval protection of rights is one of the great challenges of the contemporary democracies. 